\title{
A unified method for calculating the fire resistance of concrete-filled steel tube with fire protection under combined loading
}

\author{
Min $\mathrm{Yu}^{\mathrm{a}, \mathrm{c}}, \mathrm{Xuan} \mathrm{Hu}^{\mathrm{a}}$, Yin $\mathrm{Chi}^{\mathrm{a}}$, Jianqiao $\mathrm{Ye}^{\mathrm{b}, *}$, \\ a. School of Civil Engineering, Wuhan University, Wuhan 430072, China; \\ b. Department of Engineering, Lancaster University, Lancaster, LA1 4YR. UK; \\ c. Engineering Research Center of Urban Disasters Prevention and Fire Rescue Technology of Hubei Province, Wuhan \\ 430072, China;
}

\begin{abstract}
Prediction of temperature field is a critical step in the fire resistance design of concrete filled steel tubes (CFST). Theoretically, this step is to solve a transient heat conduction problem defined in a composite medium, of which analytical solutions are either very complex or not available in an explicit form. Though the problem can be solved satisfactorily by various numerical methods, it is not easy and convenient for engineers to implement the methods in practical design or include them in design codes. It has been shown recently, instead of calculating the distribution of temperature, the average temperature over the cross section of a CFST can be used in the calculation of its fire resistance. Based on the average temperature, this paper aims at providing a unified analytical solution for calculating fire resistance of circular and equilateral polygonal CFST columns with or without protection. A simplified method for calculating average temperature over a CFST cross section with or without protective coating is developed and validated, which can take the effect of cross sectional shape and material thermal properties into consideration. The simple temperature calculation method is incorporated into the unified method to calculate the fire resistance of CFST columns with or without protective coating. Comparisons are made between the calculation results using the new equations with those from other existing methods and experiments, which suggest that the newly developed unified method can predict the average temperature and the fire resistance fCFST columns satisfactorily.
\end{abstract}

Keywords: Concrete filled steel tube (CFST), Hollow and solid section, Circular and polygonal section, Fire, Average temperature

\author{
Nomenclature \\ $A_{c}, A_{c c}$ \\ area of concrete, area of concrete under compression \\ $A_{k}$ \\ area of hollow \\ $A_{s}, A_{s c}, A_{s t}$ \\ area of steel, area of steel under compression, area of steel under tension \\ $C, C_{s c}, C_{s p}$ \\ circumferences of CFST column, circular CFST column and polygonal CFST column \\ $D, d_{s}, d_{p}$ \\ diameter of the column, thickness of steel tube and thickness of protective coat respectively
}




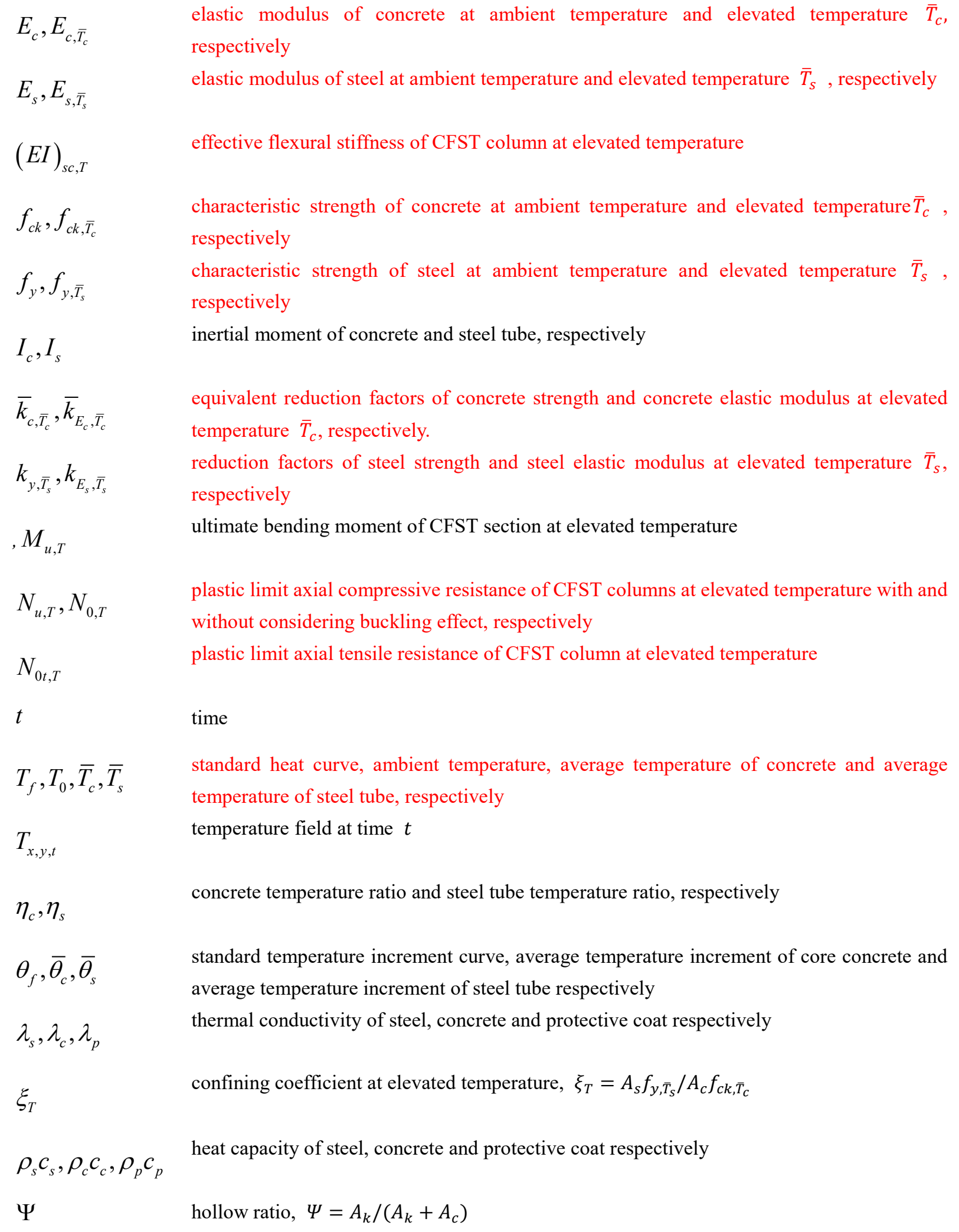

\section{Introduction}

Fire resistance of concrete-filled steel tube (CFST) columns is one of the most crucial factors that must be 
considered in the design process of modern building structures. For example, structural fire design is amongst the most important design stages in Euro Code $4^{[1]}$, DBJ13-5 ${ }^{[2]}$, ASCE/SFPE 29-99 $9^{[3]}$ and ACI $216^{[4]}$. There are many different forms of CFST columns characterized by their cross-sectional profiles, as shown in Fig. 1, where num refer to the number of sides of the cross section, and $\Psi$ denotes the hollow ratio of the CFST column.

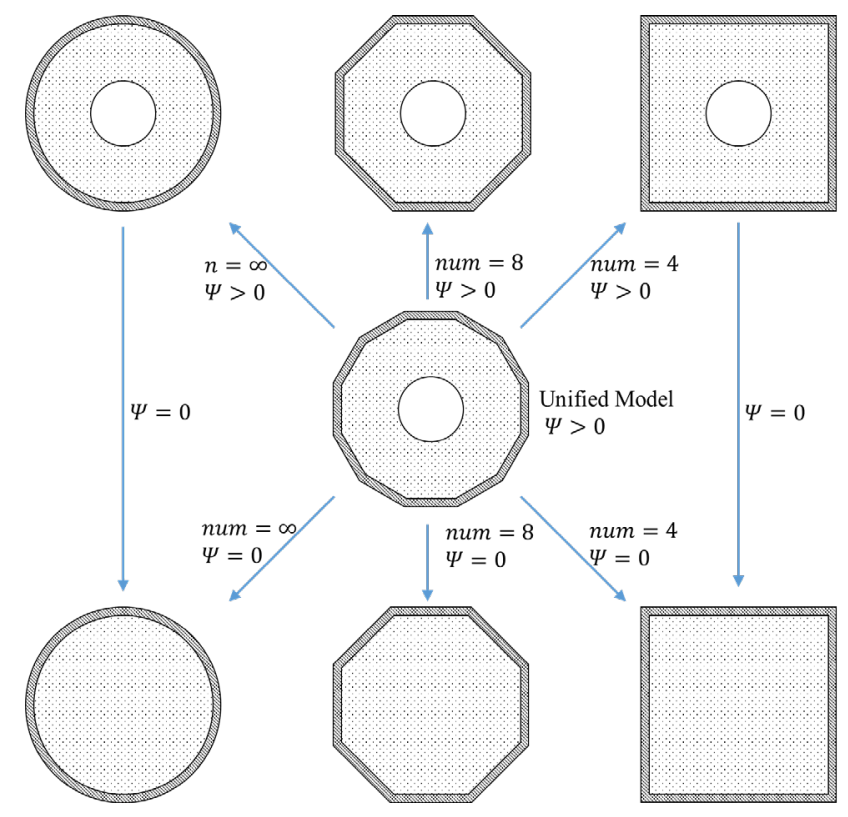

Fig. 1 Section profiles of CFST characterized by their internal hollow and number of sides

There have been extensive experimental research studies on structural performance of concrete-filled steel tubes under fire conditions (e.g. ${ }^{[5-11]}$ ). Since fire experiments are complex and expensive, numerical simulations have played an important role in studying the behavior of CFST columns under fire. These include the work done on the fire resistance of concrete filled steel tube by Lie (1990) ${ }^{[12]}$, Hong (2005) ${ }^{[13]}$, Han (2007) ${ }^{[14]}$, Ding and Wang (2008) ${ }^{[15]}$, Espinos (2010) ${ }^{[16]}, \mathrm{Yu}(2010)^{[17]}, \mathrm{Lu}(2011){ }^{[18]}$, Yang (2013) ${ }^{[19]}$ Yao (2016) ${ }^{[20]}$, Guo (2017) ${ }^{[21]}$ and Ibanez (2019) ${ }^{[22]}$. Traditionally, thermal analyses of composite structural members are mainly based on using prescriptive codes that were established empirically, while there is a worldwide trend nowadays towards a more flexible performance-based building fire code, where handy and accurate formulations for thermal analyses of structures under fire conditions are of paramount importance.

According to relevant research ${ }^{[16,23]}$, the fire resistance calculation method proposed in Annex H of EN1994-1-2 for CFST columns was proved to be unsafe, which led to a recent inclusion of an amendment stating that the relative slenderness of the columns should be less than 0.5 for the use of the method. Under this context, a number of practical design formulas were proposed by many researchers, e.g., Kodur $(1998)^{[24]}$, who conducted parametric analysis through experiments and numerical calculations, and proposed formulas for calculating fire resistance of solid circular and square CFST columns using regression analysis; Wang and Kodur (1999 ${ }^{[25]}$ developed an approach for evaluating squash load and rigidity of solid CFST columns at elevated temperature based on Euro Code $4^{[1]}$. Wang $(2000)^{[26]}$ presented a method for circular CFST columns with and without fire protection, which required point interpolation to obtain the squash load and rigidity of a column. Li et al. (2001) ${ }^{[27]}$ proposed a formula for the bearing capacity of solid circular CFST columns under fire on the basis of parametric analysis and regression. Han et al. $(2002)^{[28]}$ proposed a formula to determine the strength index of circular and square solid CFST columns based on the results of parametric and experimental studies, and a formula for calculating the thickness of fireproof. Tan and Tang 
(2004) ${ }^{[29]}$ applied the Rankine method to the analysis of reinforced and plain solid CFST columns at elevated temperature. For most of the above methods, a known temperature distribution on the cross section of a concrete filled steel tube is required.

Accurate prediction to the non-uniform temperature field of a CFST section in fire is a complex mathematical problem that requires solutions of a set of time and spatially dependent partial differential equations. It is recommended in Euro Code 4 that the temperature in each sub-region of a CFST cross section could be evaluated to simplify the calculation ${ }^{[1]}$. Although the computation costs have been drastically reduced via this method, it is still not suitable for implementation in practical design. To deal with this challenge, Yu (2011) ${ }^{[30]}$ presented a method based on the average temperature on the cross section to calculate fire-resistant of CFST columns under axial compressive load, which have been successfully applied to the analyses of solid and hollow CFST columns of circular and equilateral polygon sections. Espinos, et al $(2012,2013)^{[31,32]}$ presented a simple method for evaluating fire resistance of circular solid CFST columns based on Euro Code 4, where the concept of equivalent temperature was adopted, and proposed an approach to calculate bearing capacity of solid circular, elliptical and reinforced circular concrete filled steel tubes. These methods were, however, applicable only for CFST columns without any fire protections.

On the basis of the method proposed by the authors in the previous work ${ }^{[33-35]}$ for calculating fire resistance of unprotected CFST columns, this paper studies CFST columns with fire protection and develops a unified method that includes the solutions of circular and equilateral polygonal CFST columns with and without fire protection. The method adopts the average temperature concept proposed previously by the authors. In this paper, the effect of cross section shape and the thermal properties of materials on the calculation of average temperature are studied. Validated by numerical simulations, a simple method for calculating average temperature of concrete and steel is proposed for CFST columns with or without protective coating. Furthermore, the unified method is applied to calculate fire resistance of CFST columns with or without protection, where comparisons are made between the results of the current method and those of other researchers, including experimental results.

\section{Calculation of fire resistance of CFST columns with protection}

\subsection{Review of the unified method for unprotected CFST columns}

In this section, the authors' previous work on the unified method for predicting fire resistance of CFST columns of various geometry without fire protection is reviewed ${ }^{[33-35]}$. The main framework of the unified method is shown in Fig. 2. Based on the average temperature concept, the essence of the unified method is to replace the material properties of concrete and steel at room temperature with their equivalent material properties at elevated temperature so that the fire resistance of a CFST column at any given time under fire can be obtained. The calculation procedure is simple and straightforward, including the following main steps. (a) From the average temperature of steel tube and concrete core, a set of equivalent material reduction factors is computed. (b) With the reduction factors, the mechanical properties of steel and concrete under elevated temperature, e.g, the strength and elastic modulus of steel and concrete can be calculated, and (c) Using the reduced material properties in the formulas for the room temperature provides the unified formulation for fire resistance prediction at elevated temperature. More details of the approach can be found in the Appendix. 


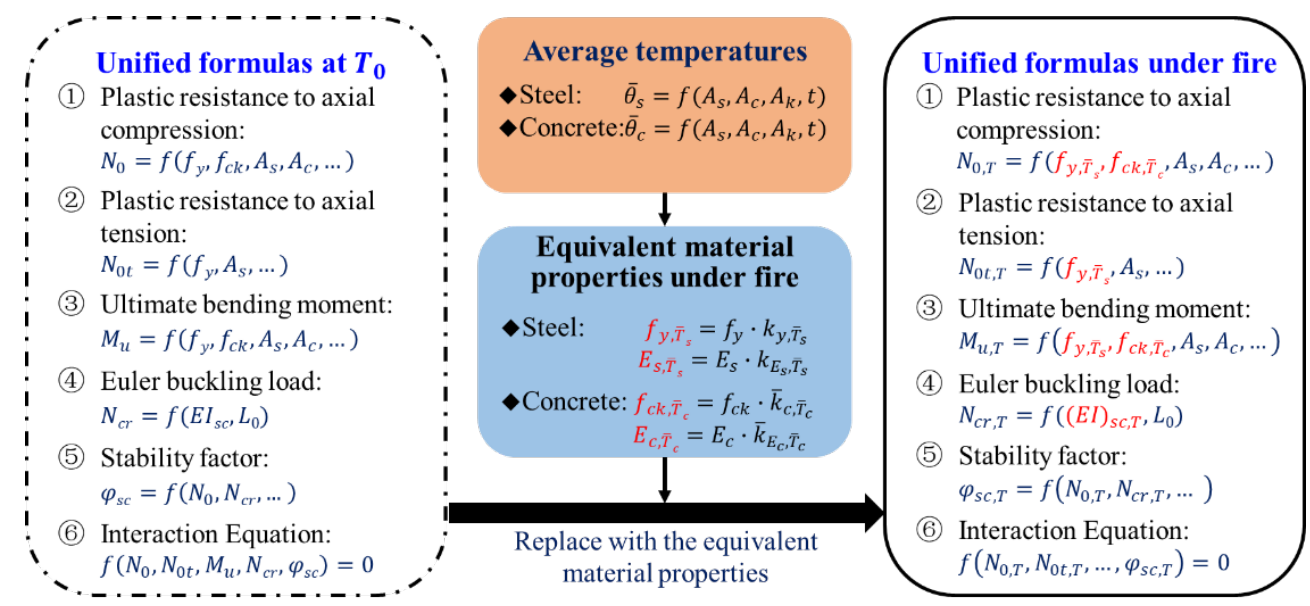

Fig. 2 The unified method for CFST columns under fire

The method has a number of advantages. One of the unique features is that this unified method is valid for a range of columns that can be solid, hollow, circular, polygonal, short or long. Another feature is that thermal and mechanical analyses can be decoupled to allow sufficient flexibility to deal with various scenarios. For example, to cover a range of different types of concrete and steel, the unified method can take into account of their respective material deterioration effect and their different mechanical behavior under fire by adopting corresponding sets of reduction factors. Moreover, the unified method at ambient temperature can calculate the resistance of not only CFST columns but also plain concrete columns and steel tubes without concrete fillings, which means that the valid range of confining coefficient at ambient temperature, $\xi=f_{y} A_{s} / f_{c k} A_{c}$, can be from 0 to $\infty$, where $\xi=0$ refers to a plain concrete column while $\xi \rightarrow \infty$ represents a steel tube. The most significant highlight of the unified method is that it is applicable to CFST columns at both ambient and elevated temperature.

The unified method has been proved to be effective in calculating the mechanical behavior of unprotected CFST columns in previous research ${ }^{[33-35]}$, However, the method has not be applied to protected CFST columns. In this paper, the unified method is extended to include protected CFST columns under fire. In Section 2.2, the general principle of the method is introduced. In Sections 2.3 to 2.5, the applicability of the unified method under different loading patterns are discussed.

\subsection{Plastic limit analysis of CFST columns with fire protection}

For a CFST column at ambient temperature and its plastic limit state, the steel tube is fully yielded and the concrete core in compression reaches its compressive strength. In practical designs, the tensile strength of the concrete is normally neglected. This applies also to a CFST column under fire. According to Euro Code $4^{[1]}$, elevated temperature will reduce the strength and the elastic modulus of both the concrete core and the steel tube. In the meantime, it is found that the confinement effect can be neglected after CFST columns being exposed to fire more than 10 minutes $^{[33-35]}$. Thus the axial force $N$ and the bending moment $M$ on the critical cross section under the combined load are calculated by Eq. (1) and (2), respectively, e.g., for the polygonal cross section shown in Fig. 3.

$$
\begin{gathered}
N=\iint_{A_{c c}} f_{c k, x, y, T} d A+\iint_{A_{s c}} f_{y, x, y, T} d A-\iint_{A_{s t}} f_{y, x, y, T} d A \\
M=\iint_{A_{c c}} y \cdot f_{c k, x, y, T} d A+2 \iint_{A_{s c}} y \cdot f_{y, x, y, T} d A
\end{gathered}
$$


where $f_{c k, x, y, T}$ and $f_{y, x, y, T}$ are the respective strength of concrete and steel at position $(x, y)$ at temperature $T$. They can be computed by $f_{c k, x, y, T}=k_{c k, x, y, T} f_{c k}$ and $f_{y, x, y, T}=k_{y, x, y, T} f_{y}$, respectively, where $k_{c k, x, y, T}$ and $k_{y, x, y, T}$ are the strength reduction factors at position $(x, y)$ at temperature $T$.

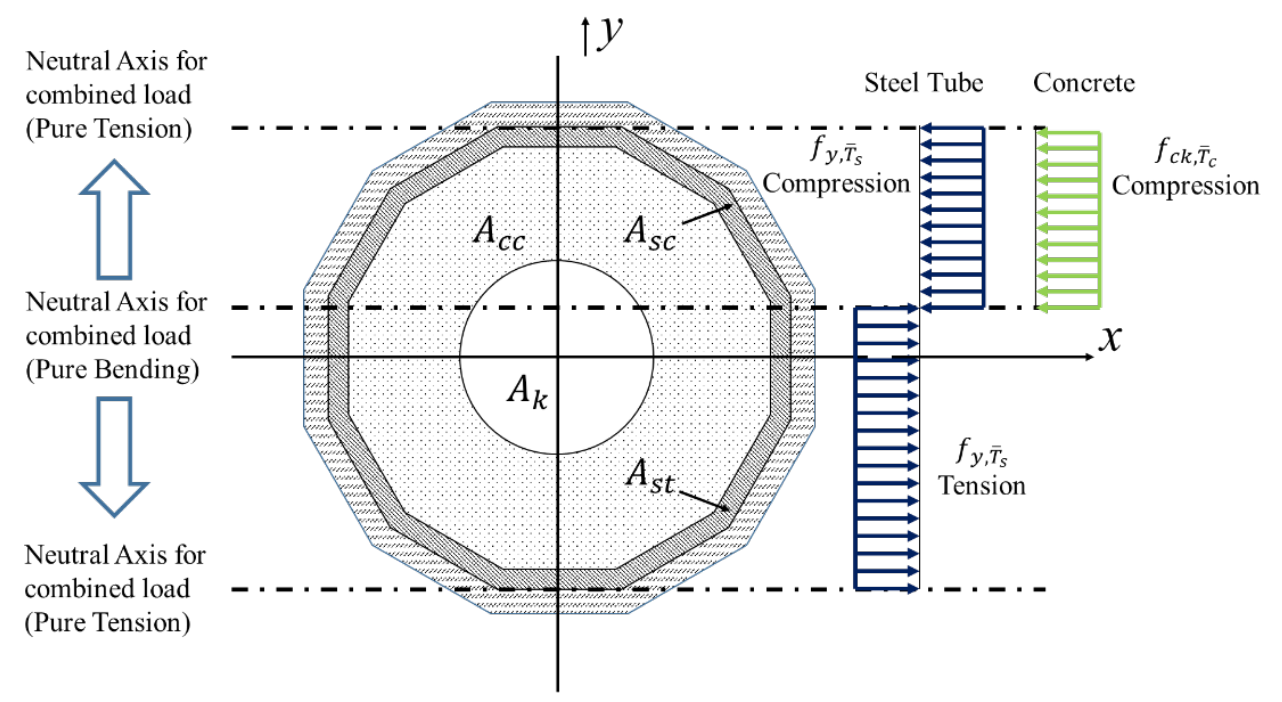

Fig. 3 CFST section under fire subjected to compressive and bending load

Similarly, the effective stiffness of a CFST column under fire can be calculated by

$$
(E I)_{s c, T}=\iint_{A_{s}} y^{2} E_{s, x, y, T} d A+\iint_{A_{c}} y^{2} E_{\mathrm{c}, x, y, T} d A
$$

In Eq.(3), $E_{s, x, y, T}=k_{E_{s}, x, y, T} E_{s}$ and $E_{c, x, y, T}=k_{E_{c}, x, y, T} E_{c}$ respectively. $k_{E_{s}, x, y, T}$ and $k_{E_{c}, x, y, T}$ are the stiffness reduction factors at position $(x, y)$ at temperature $T$. The stiffness and the strength reduction factors mentioned above can be found or derived from a number of published literature ${ }^{[1,14,36]}$.

It is apparent that the distribution of temperature field over a CFST cross section is crucial to complete the calculation of Eq. (1). When a CFST column is under fire, it is assumed that the temperature field is independent of the longitudinal direction while the distribution in the transverse direction is non-uniform. Hence, the temperature field is described as a function of coordinates $x, y$ and time $t$, i.e., $T_{x, y, z, t}=T_{x, y, t}$, so that determination of the temperature field requires solution of the following $2 \mathrm{D}$ heat transfer problem.

\section{a) Governing equation}

The governing equation is shown in Eq. (4).

$$
\rho_{\alpha} c_{\alpha} \frac{\partial T_{x, y, t}}{\partial t}+\nabla \cdot\left[-\lambda_{\alpha} \nabla T_{x, y, t}\right]=0
$$

where $T_{x, y, t}$ is the temperature field of the cross section; $\rho_{\alpha} c_{\alpha}$ refers to heat capacity of material and $\lambda_{\alpha}$ is thermal conductivity. The subscript, $\alpha$, takes $p$ for fire protection, $s$ for steel and $c$ for concrete. To calculate the temperature field, these temperature-dependent thermal properties should be given a priori. It is worth noting that the thermal properties of concrete available in the literature are sometime significantly different, as they may have been measured using different techniques and from different concrete. ${ }^{[1,7]}$. In this paper, the thermal properties of concrete and steel, i.e. $\rho_{c} c_{c}, \rho_{s} c_{s}, \lambda_{c}$ and $\lambda_{s}$, recommended by Lie ${ }^{[7]}$ are adopted, further details are given in Section 3.2. As for protective coating, there are two commonly used non-intumescent materials, namely specialist fire proof coating 
and cement mortar, the thermal properties of which can be found in $\operatorname{Han}^{[14]}$. In this section, the specialist fireproof coating is considered. The thermal properties of the coating are defined as $\rho_{p} c_{p}=5 \times 10^{5} \mathrm{~J} /\left(\mathrm{m}^{3} \cdot \mathrm{K}\right)$ and $\lambda_{p}=$ $0.1 \mathrm{~W} /(\mathrm{m} \cdot \mathrm{K})$. The effect of the type of protective coating will be discussed in Section 3.4.

\section{b) Boundary conditions}

Apart from the governing equation, boundary conditions are also critical to the solution. In this paper, the heat flux in-flow from the environment at time $t$ is mainly comprised of both heat convection and radiation. For the interface between the steel tube and the concrete, a continuous temperature field is assumed. In addition, if the concrete core is hollow, the internal boundary is assumed to be fully adiabatic. Therefore, the boundary conditions can be expressed as follows.

$$
\begin{gathered}
-n_{p o} \cdot\left(-\lambda_{p} \nabla T_{p o}\right)=h\left(T_{f}-T_{p o}\right)+\varepsilon \sigma\left(T_{f}^{4}-T_{p o}^{4}\right) \\
T_{p i}=T_{s o}, T_{s i}=T_{c o} \\
-n_{c i} \cdot\left(-\lambda_{c} \nabla T_{c i}\right)=0
\end{gathered}
$$

In Eq.(5) to Eq.(7), $T_{f}$ is the prescribed surrounding temperature that is normally described by following the standard heat curve specified by, e.g., either ISO-834 or ASTM-E119; $\lambda_{p}$ denotes thermal conductivity of fireproof; $T$ stands for temperature; $n$ refers to the normal direction of boundary; The subscripts $p o, p i, s o, s i, c o$, and $c i$ denote the outer surface of fireproof, inner surface of fireproof, outer surface of steel tube, inner surface of steel tube, outer surface of concrete and inner surface of concrete, respectively. $h, \varepsilon$ and $\sigma$ are heat convection coefficient, heat radiation coefficient and the Stefan-Boltzmann constant, respectively. More details of the model are described in the previous work by Wang and $\operatorname{Tan}^{[37]}$ and Yu et al ${ }^{[17]}$.

By solving the partial differential equation presented in Eqs. (4) to (7), the temperature field on the cross section of a CFST column can be readily obtained. In this paper, it is calculated by COMSOL. The heat transfer module which is embedded in COMSOL is adopted to solve the governing equation subjected to the initial and boundary conditions. The numerical calculation is completed by using the transient solver.

\subsection{N-M interactive curves of CFST columns with fire protection}

After the temperature is determined, the integrals in Eqs. (1) and (2) can be calculated, from which the N-M relation of a CFST column under fire is obtained. To this end, circular CFST columns with different diameters, steel thickness, hollow ratios and thickness of protective coating are selected to carry out the numerical simulations. Since the applicable range of the diameter is defined as [200 $\mathrm{mm}, 2000 \mathrm{~mm}$ ] in Chinese Code GB50936-2014[38], in order to cover all possible values in practical design, the values ranging from $100 \mathrm{~mm}$ to $2100 \mathrm{~mm}$ is adopted in this paper. A summary of the chosen columns is shown in Table 1, where there are a total of 864 different designs. Table 1 The parameters and design of CFST cross section under fire

\begin{tabular}{ccccccc}
\hline Index & 1 & 2 & 3 & 4 & 5 & 6 \\
\hline Diameter $D(\mathrm{~mm})$ & 100 & 500 & 900 & 1300 & 1700 & 2100 \\
Thickness of steel $d_{s}(\mathrm{~mm})$ & 1 & 5 & 9 & 13 & 17 & 21 \\
Hollow ratio $\Psi$ & 0.00 & 0.15 & 0.30 & 0.45 & 0.60 & 0.75 \\
Thickness of fireproof $d_{p}(\mathrm{~mm})$ & 0 & 3 & 5 & 10 & - & - \\
\hline
\end{tabular}

Without loss of generality, a solid CFST column (hollow ratio $\Psi=0.0$ ) of diameter $D=900 \mathrm{~mm}$ and steel 
tube thickness $d_{s}=9 \mathrm{~mm}$, and a hollow CFST column (hollow ratio $\Psi=0.6$ ) of diameter $D=500 \mathrm{~mm}$ and steel tube thickness $d_{s}=13 \mathrm{~mm}$ are chosen as representative cases. In addition, protective coatings with different thickness are added to the outer surface of the steel tube to study their influence on the mechanical behavior of the CFST columns. In the numerical calculation, the type of steel is defined as Q345 with $f_{y}=345 \mathrm{MPa}$ and the type of concrete is $\mathrm{C} 60$ with $f_{c k}=38.5 \mathrm{MPa}$. It is worth noting that $f_{c k}$ refers to the characteristic compressive strength of concrete defined in Chinese Code GB50010-2010 (2015 version) ${ }^{[39]}$, measured by prism test with 95\% guarantee. By changing the position of the neutral axis, the N-M interaction curves at varying temperature relative to time are obtained and shown in Fig. 4.

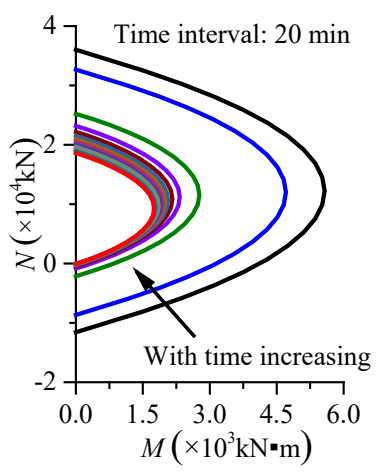

a) Solid section with 0 mm coating

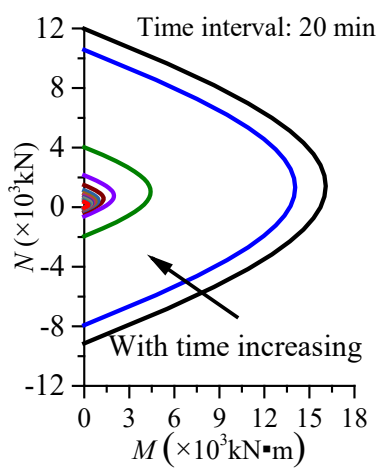

e) Hollow section with 0 mm coating

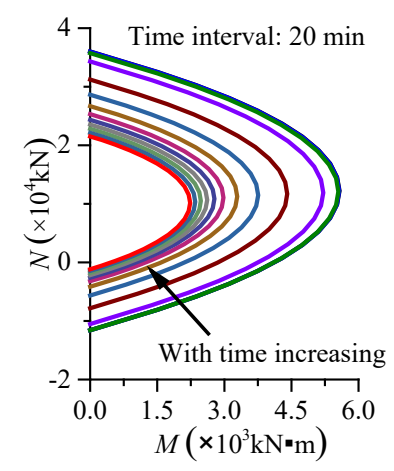

b) Solid section with 3 mm coating

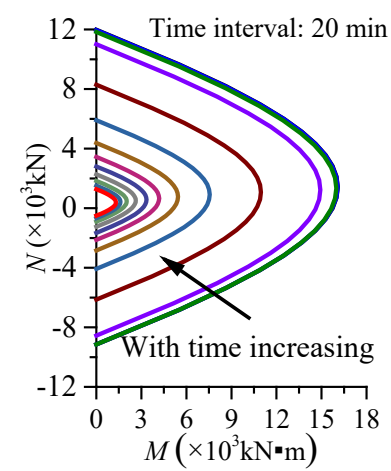

f) Hollow section with 3 mm coating

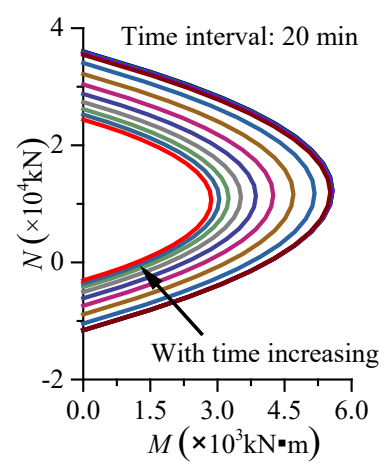

c) Solid section with 5 mm coating

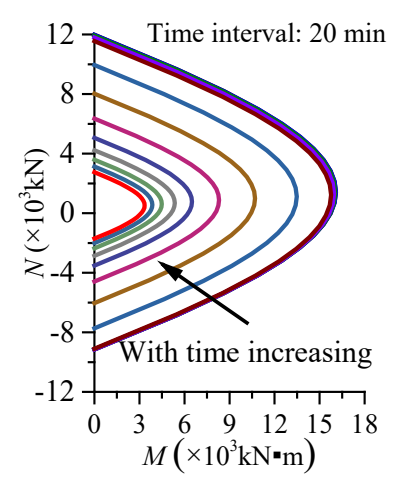

g) Hollow section with 5 mm coating

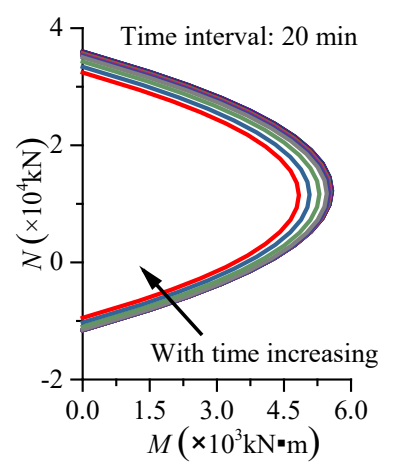

d) Solid section with 10 mm coating

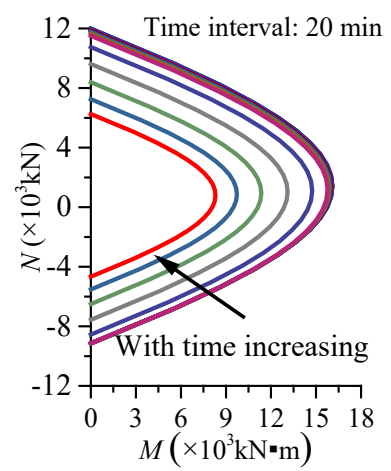

h) Hollow section with 10 mm coating

Fig. 4 N-M interaction curves

In Fig. 4, the curves on the far right of each figures are the N-M relations at ambient temperature while the curves on the far left are the ones at 240 minutes of fire exposure time. The curves are plotted at every 20 minutes. It can be seen in Fig. 4 that, as expected, for both the solid and hollow sections, the fire resistance of the columns increases with the increase of the thickness of the fireproof. In the authors' previous research ${ }^{[35]}$, it was concluded that that the N-M interaction curves of a CFST column without fire protection could be approximately represented by the following quadratic equation.

$$
\frac{M}{M_{u, T}}=\left(1-\frac{N}{N_{0, T}}\right)\left(1-\frac{N}{N_{0 t, T}}\right)
$$

In Eq.(8), $M_{u, T}$ denotes ultimate bending moment; $N_{0, T}$ refers to the plastic resistance of a CFST column under compression without considering secondary effect; $N_{0 t, T}$ is the plastic resistance of a CFST column under tension. 
The values of $N_{0, T}$ and $N_{0 t, T}$ can be directly extracted from the intersections of the curves with the N-axis in Fig. 4 and the maximum $\mathrm{M}$-value of each curves are the respective $M_{u, T}$.

In order to demonstrate the applicability of Eq. (8) to the CFST columns with fire protection, the N-M curves of all the CFST columns are re-plotted in the form of $M / M_{u, T}$ against $\left(1-N / N_{0, T}\right)\left(1-N / N_{0, t, T}\right)$, as shown in Fig. 5, According to Fig. 5, the mean value of $M / M_{u, T}$ against $\left(1-N / N_{0, T}\right)\left(1-N / N_{0, t, T}\right)$ is 1.00 and the variance is 0.0021, so it is evident that Eq.(8) is also satisfied. Consequently, it is concluded that the N-M interaction equation established for unprotected CFST columns applies also to the CFST columns with fire protection.

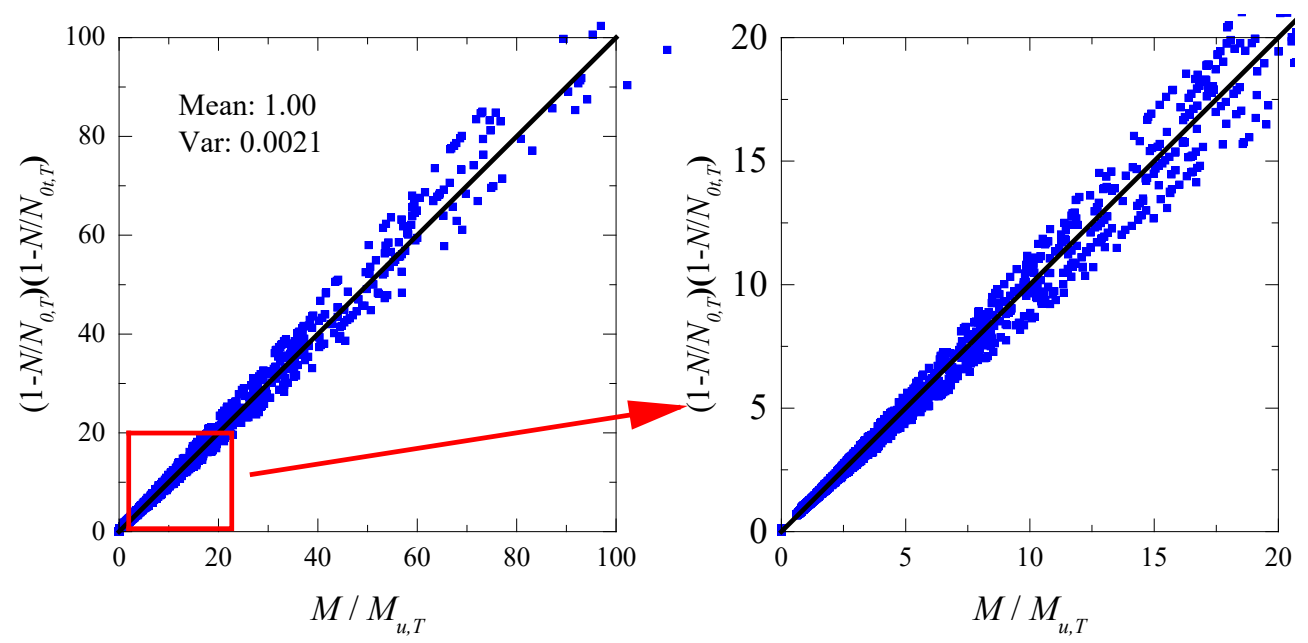

Fig. 5 Verification of N-M interaction equation

Moreover, according to the theoretical analysis conducted in the previous research ${ }^{[35]}$, if a CFST column satisfies the interaction equation(8), where the second order effect was ignored, the interaction equation can be extended to include the higher order effect of combined loading as follows.

$$
\frac{\beta_{m} M}{M_{u, T}}=\left(1-\frac{N}{\varphi_{s c, T} N_{0, T}}\right)\left(1-\frac{\varphi_{s c, T} N}{N_{0 t, T}}\right)\left(1-\frac{\varphi_{s c, T} N}{N_{c r, T}}\right)
$$

In Eq.(9), $\beta_{m}$ is the coefficient of equivalent bending moment and its value can be taken from practical design codes $^{[40]} ; N_{c r, T}$ is the Euler critical axial resistance under high temperature, which is a function of effective stiffness, $(E I)_{s c, T}$, of a CFST column under fire; $\varphi_{s c, T}$ is the stability coefficient of a CFST column under high temperature, which is also a function of $(E I)_{s c, T}$. Hence, in order to determine the fire resistance of a CFST column under combined loading, $N_{0, T}, N_{0 t, T},(E I)_{s c, T}$ and $M_{u, T}$ must be calculated in advance. Unfortunately, since these crucial parameters are normally obtained by numerical integrations, it is unrealistic to adopt the solutions in practical designs. Therefore, it is vitally important for engineers to have a simple and straightforward calculation method for calculating these parameters.

\subsection{Axial resistance of CFST columns with protection based on average temperature}

When a CFST column is subjected to axial compression, the area of the compression zone is equal to the total cross sectional area, i.e. $A_{c c}=A_{c}, A_{s c}=A_{s}$ and the area of tension zone is zero, i.e. $A_{s t}=0$. When the column is subjected to axial tension, it is assumed that the steel tube carries all the tensile load, i.e. $A_{c c}=0, A_{s c}=0$ and $A_{s t}=$ $A_{s}$. Apart from this, the effective flexural stiffness can also be readily calculated according to Euro Code 4.

In the authors' previous work ${ }^{[33]}$, a simple method based on average temperature was proposed to calculate the 
plastic resistance and the flexural stiffness of CFST columns. The average temperature is defined by Eq. (10).

$$
\bar{T}_{\alpha}=\frac{\iint_{A_{\alpha}} T_{x, y, t} d A}{A_{\alpha}}
$$

where $\bar{T}_{\alpha}$ and $T_{x, y, t}$ denote, respectively, the average temperature and the actual temperature field over a cross sectional area of $A_{\alpha}$. The subscription $\alpha$, takes $s$ for steel and $c$ for concrete.

To calculate the plastic resistance $N_{0, T}$ and the flexural stiffness $(E I)_{s c, T}$ of a CFST column, the contribution from the steel and the concrete are considered separately in the following sections.

\subsubsection{Steel tube}

Due to the high thermal conductivity and small thickness, the temperature field of the steel tube can be regarded as uniform. In this case, the temperature at any position within the steel tube is equal to the average temperature over its cross section, which can be expressed as $T_{x, y, t}=\bar{T}_{S}$. Hence, the reduction factors, $k_{s, T}$ and $k_{E_{S}, T}$ are both constant. Therefore, the compressive and tensile plastic resistances and the flexural stiffness of the steel tube without considering buckling effect, i.e., $N_{0, s, T}, N_{0 t, T}$, and $(E I)_{s, T}$, can be calculated by Eqs. (11), (12) and (13).

$$
\begin{gathered}
N_{0, \mathrm{~s}, T}=\iint_{A_{s}} k_{s, T} f_{y} d A=k_{s, \bar{T}_{s}} f_{y} A_{s} \\
N_{0 t, T}=\iint_{A_{s}}-k_{s, T} f_{y} d A=-k_{s, \bar{T}_{s}} f_{y} A_{s} \\
(E I)_{s, T}=\iint_{A_{s}} y^{2} k_{E_{s}, x, y, T} E_{s} d A=k_{E_{s}, \bar{T}_{s}} E_{s} I_{s}
\end{gathered}
$$

In the authors' previous work ${ }^{[33]}$, the reduction factors of steel, which are functions of the average temperature, have been calibrated for unprotected CFST columns. As for the CFST columns with protection, since the temperature field is still uniform in the steel tube, the reduction factors can be readily calculated as long as the temperature of the steel is known.

\subsubsection{Core concrete}

Concrete has a much lower thermal conductivity, resulting in large temperature gradient across the concrete thickness. According to Euro Code 4, plastic resistance $N_{0, c, T}$ and flexural stiffness, $(E I)_{c, T}$, have to be evaluated by performing integrations ${ }^{[1]}$. Alternatively, the integrals can be calculated by the mean value theorem for integrals, i.e., by using Eqs. (14) and (15).

$$
\begin{aligned}
N_{0, \mathrm{c}, T} & =\iint_{A_{c}} f_{c k, x, y, T} d A=\bar{k}_{c, \bar{T}_{c}} f_{c k} A_{c} \\
(E I)_{c, T} & =\iint_{A_{c}} y^{2} E_{c, x, y, T} d A=\bar{k}_{E_{c}, \bar{T}_{c}} E_{c} I_{c}
\end{aligned}
$$

where $\bar{k}_{c, \bar{T}_{c}}$ and $\bar{k}_{E_{c}, \bar{T}_{c}}$ are the equivalent reduction factors, which are functions of the average temperature of concrete $^{[33]}, \bar{T}_{c}$. The two equivalent factors can be calculated as follows.

$$
\tilde{k}_{c, \tilde{T}_{c}}=\bar{k}_{c, \bar{T}_{c}}=\frac{\iint_{A_{c}} k_{c, x, y, T} d A}{A_{c}}
$$




$$
\tilde{k}_{E_{c}, \tilde{T}_{c}}=\bar{k}_{E_{c}, \bar{T}_{c}}=\frac{\iint_{A_{c}} y^{2} k_{E_{c}, x, y, T} d A}{I_{c}}
$$

Based on the material reduction factors defined in Euro Code 4, the explicit expressions of the equivalent reduction factors of the concrete in a CFST column without fire protection, i.e. $\bar{k}_{c k, \bar{T}_{c}}$ and $\bar{k}_{E_{c}, \bar{T}_{c}}$, have been developed in the authors' previous work ${ }^{[33]}$, which are shown in Eq. (18) and Eq. (19). It is worth noting that the equivalent reduction factors based on other design codes or research can also be calculated in the same way.

$$
\begin{aligned}
& \bar{k}_{c k, \bar{T}_{c}}=e^{-\left(\frac{\bar{T}_{c}-20}{622}\right)^{2.5}} \quad 20^{\circ} \mathrm{C} \leq \bar{T}_{c} \leq 1200^{\circ} \mathrm{C} \\
& \bar{k}_{E_{c}, \bar{T}_{c}}=e^{-\left(\frac{\bar{T}_{c}-20}{211}\right)} \quad 20^{\circ} \mathrm{C} \leq \bar{T}_{c} \leq 1200^{\circ} \mathrm{C}
\end{aligned}
$$

In order to check if the above equations are applicable to columns with fire protection, the predictions from Eqs. (18) and (19) are compared with the numerical simulations of the columns with protection, i.e. the solutions of Eqs (16) and (17).

After completing the numerical calculation, the average temperature of concrete, $\bar{T}_{c}$, as well as its equivalent reduction factors, $\bar{k}_{c, \bar{T}_{c}}$ and $\bar{k}_{E_{c}, \bar{T}_{c}}$ can be computed by Eqs. (16) and (17), and the results are extracted from 0 to 4 hours with 10 minute intervals. Thus, for a fireproof thickness, the number of numerical data points are $6 \times 6 \times$ $6 \times 25=5400$. The comparisons between the numerical data and those calculated from Eqs. (18) and (19) are presented in Fig. 6.
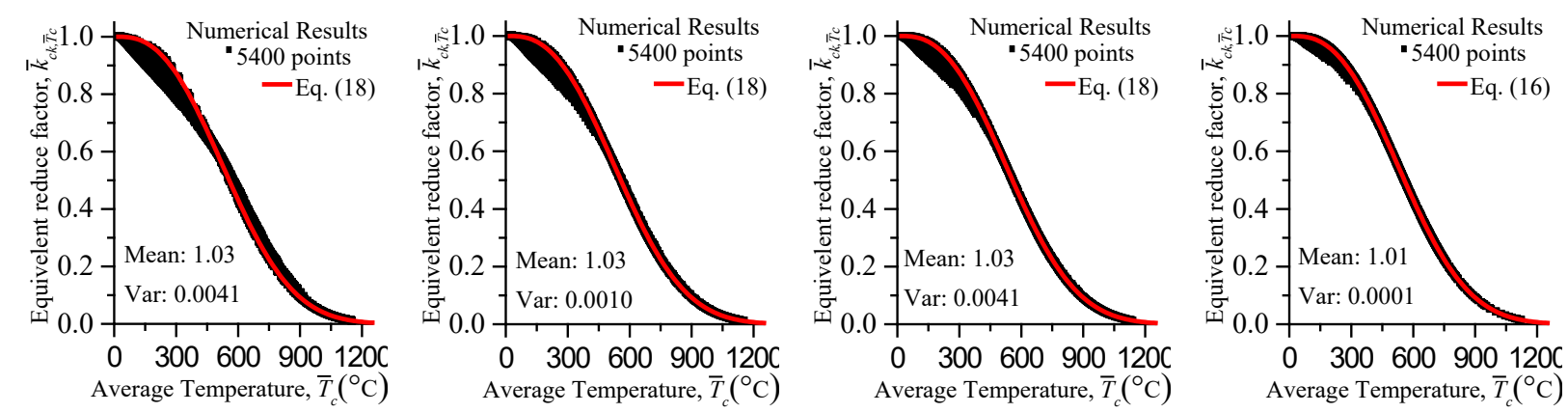

a) $\bar{k}_{c k, \bar{T}_{c}}$ with $0 \mathrm{~mm}$ coat

b) $\bar{k}_{c k, \bar{T}_{c}}$ with $3 \mathrm{~mm}$ coat

c) $\bar{k}_{c k, \bar{T}_{c}}$ with $5 \mathrm{~mm}$ coat

d) $\bar{k}_{c k, \bar{T}_{c}}$ with $10 \mathrm{~mm}$ coat
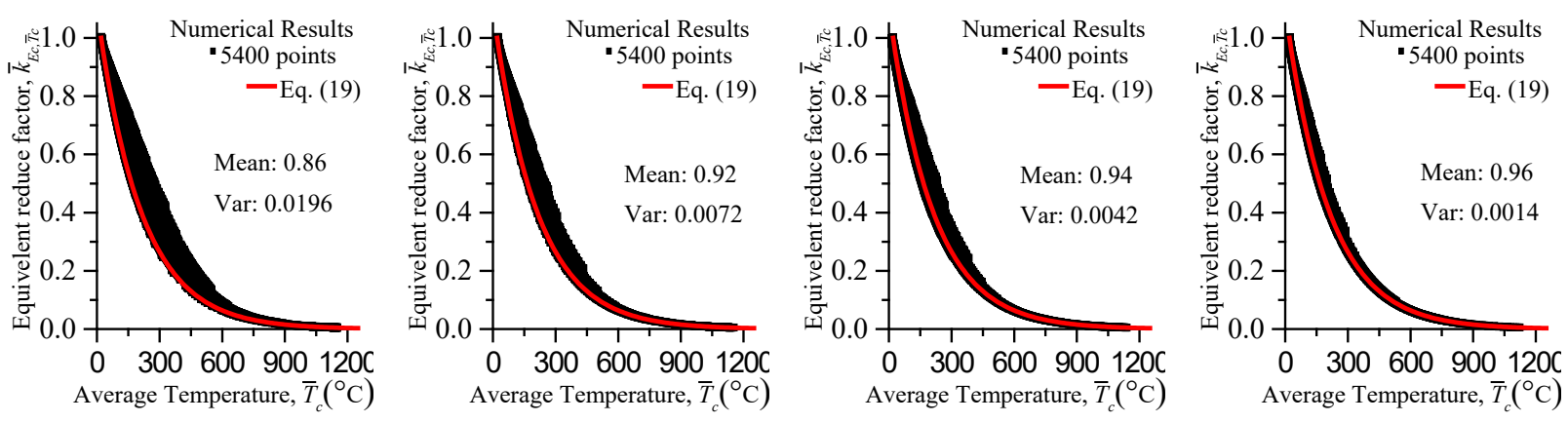

e) $\bar{k}_{E_{c}, \bar{T}_{C}}$ with $0 \mathrm{~mm}$ coat

f) $\bar{k}_{E_{c}, \bar{T}_{c}}$ with $3 \mathrm{~mm}$ coat

g) $\bar{k}_{E_{c}, \bar{T}_{c}}$ with $5 \mathrm{~mm}$ coat

h) $\bar{k}_{E_{C}, \bar{T}_{C}}$ with $10 \mathrm{~mm}$ coat

Fig. 6 Equivalent reduction factors of concrete with different thickness of protective coating

The average value and variance of numerical results versus analytical results are presented in Fig. 6. In general, the predictions of Eq. (18) and Eq. (19) agree with the numerical results reasonable well. It can also be seen that the 
predictions from the equations show better agreement with the numerical results when the thickness of the protective coating is greater, which is mainly attributed to the fact that the temperature gradient in the concrete core is less steep. From the above comparisons, it can be concluded that the previously proposed Eqs. (18) and (19) are also valid for CFST columns with protection.

\subsection{Ultimate bending moment of CFST columns with protection based on average temperature}

Based on the N-M interaction curves calculated in Section 2.3, the ultimate bending moment of CFST columns with protection are studied in this section. In fact, the ultimate bending moment can be extracted from Fig. 4 by letting $N=0$.

According to the theoretical analysis in the authors' previous research ${ }^{[34]}$, the ultimate bending moment can be calculated as follows.

$$
M_{u, T}=\left(1-\frac{\xi_{T}}{4\left(\xi_{T}+1\right)}\right) f_{y, \bar{T}_{s}} A_{s} \frac{D}{2}
$$

where $\xi_{T}$ denotes the confining coefficient under fire and is defined as $f_{y, \bar{T}_{S}} A_{s} / f_{c k, \bar{T}_{c}} A_{c}$. The strength of concrete at average temperature $\bar{T}_{c}$ can be determined by $f_{c k, \bar{T}_{c}}=\bar{k}_{c k, \bar{T}_{c}} f_{c k}$. Similarly, the strength of steel, $f_{y \bar{T}_{s}}$, is equal to $k_{y \bar{T}_{s}} f_{y}$.

Fig. 7 shows the comparisons between the numerical results and the predictions using Eq. (20).

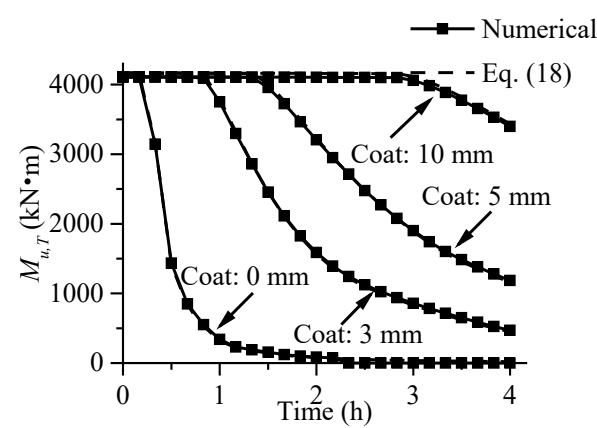

a) solid section with protective coat

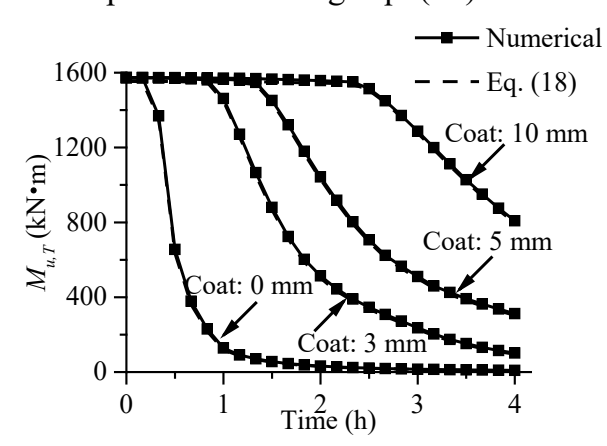

b) -Hollow section with protective coat

Fig. 7 Time- $M_{u, T}$ curves

Evidently, Fig. 7 shows excellent comparisons between the numerical simulations and the formula predictions. Fig. 7 also shows that the greater the thickness of the protective coating is, the longer the ultimate bending moment $M_{u, T}$ will remain approximately constant. The excellent agreement between the two sets of results suggest that the ultimate bending moment equation (Eq. (20)) is also valid for CFST columns with protective coating. It is worthy of mentioning that although in Sections 2.4, 2.3 and 2.5, the calculations and comparisons are for columns with a circular cross section, similar conclusions can also been made for columns with a polygonal section.

\section{Calculation of average temperature}

\subsection{Effect of cross-section shape}

After performing integration of Eq.(4) over the a cross section $A$, the governing equation of heat transfer can be rewritten in the following form. 


$$
\iint_{A} \rho c \frac{\partial T_{x, y, T}}{\partial t} d A=\oint_{C}-n_{s o} q_{s o} d C
$$

where $C$ is the boundary of the cross section; $n_{s o}$ refers to the normal direction of the outer surface of steel tube; $q_{s o}$ denotes the heat influx from the outer surface of steel tube, which is $-\lambda_{s} \nabla T_{s o}$. It is worth noting that in this paper only circular and equilateral polygonal cross sections are considered. In this sense, considering the symmetry of the section and ignoring the changes in circumferences, the integral on the right-hand side of Eq. (21) can be simplified as $C \cdot q_{s o}(t)$. Therefore, by integrating with respect to time $t$ on Eq. (21) and introducing the concept of average temperature, the following equation can be obtained.

$$
\rho c A \bar{\theta}(t)=C \int_{0}^{t} q(\tau) d \tau
$$

Especially, for a CFST member, one has the following equation.

$$
\rho_{s} c_{s} A_{s} \bar{\theta}_{s}(t)+\rho_{c} c_{c} A_{c} \bar{\theta}_{c}(t)=C \int_{0}^{t} q_{s o}(\tau) d \tau
$$

To unify the calculation of the average temperature, a polygonal cross section is transformed to an equivalent circular one with the same area, which means that both $A_{s}$ and $A_{c}$ are the same, as shown in Fig. 8. The perimeter of a polygonal column can be calculated by its equivalent circular counterpart as $C_{s p}=\sqrt{\tan \gamma / \gamma} C_{s c}, \gamma=\pi / n u m$, in which num is the number of sides of the polygonal section. For example, typical values of $\sqrt{\tan \gamma / \gamma}$ are 1.13 and 1.03 , respectively, for square and octagon sections. For a polygon having more than 12 side, it is approximate that $\sqrt{\tan \gamma / \gamma} \leq 1.01$. Since the circumference of the equivalent circular section $C_{s c}$ is approximately equal to that of the polygonal one, i.e., $C_{s p}$, for the same thermal properties $\rho_{s} c_{s}$ and $\rho_{c} c_{c}$, it is reasonable to speculate that the average temperatures of the steel tube and the concrete of the two equivalent cross sections should be approximately the same.

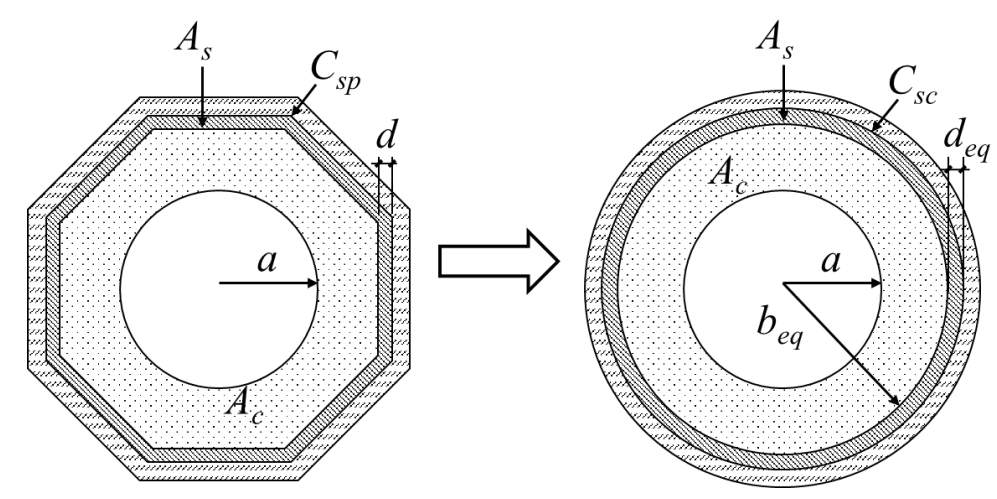

Fig. 8 Schematic diagram of cross section transformation

To support the above expectation, the average temperatures of the two representative circular sections, i.e., the solid and the hollow CFST ones presented in Section 2.3, are compared with those of their respective polygonal counterparts in Fig. 9. 


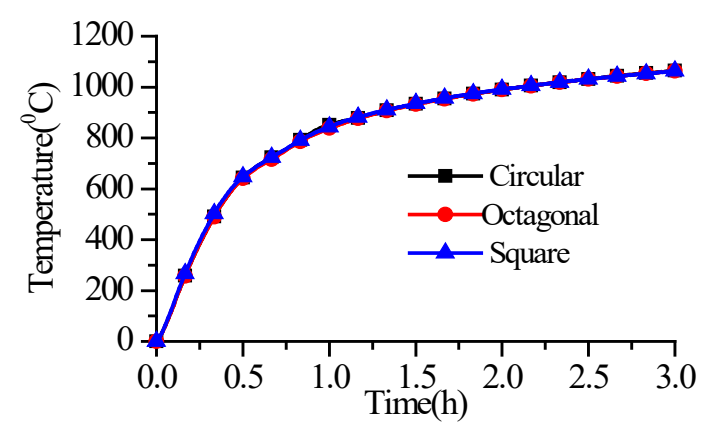

a) Steel part of the solid section

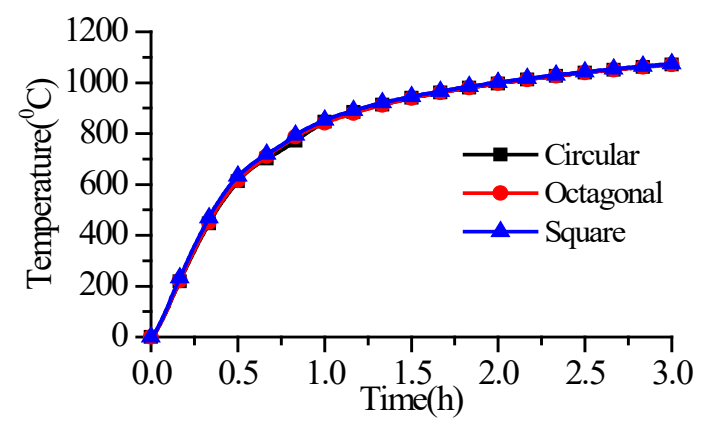

c) Steel part of the hollow section

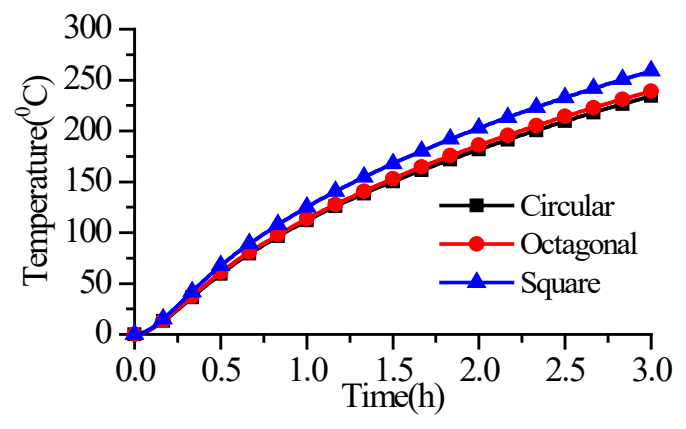

b) Concrete part of the solid section

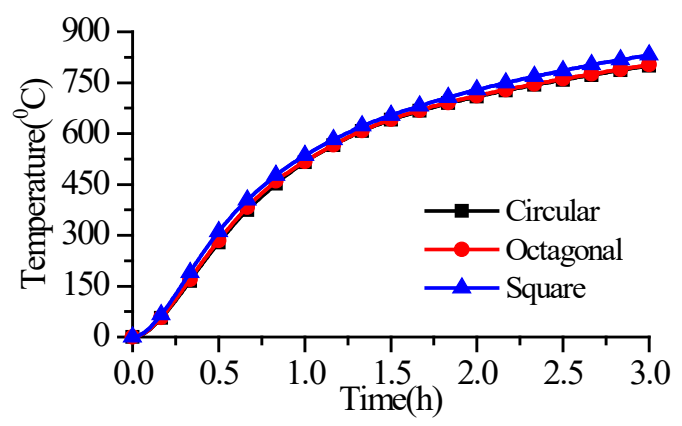

d) Concrete part of the hollow section

Fig. 9 Comparison of average temperature on different cross sections

Fig. 9 shows the time history of the average temperature in the steel and the concrete core of the polygonal solid and hollow sections, and their respective equivalent circular sections. As can be seen in Fig. 9, for both the solid and hollow sections, the average temperature of concrete of the square sections are always higher than that of the octagonal ones that have a higher temperature than the equivalent circular sections. However, the observed discrepancies are small and negligible. This observation is consistent with the above expectations. Hence, the polygonal CFST columns can be equivalently represented by their respective circular ones with the same areas in the calculation of average temperature.

\subsection{Effect of thermal properties}

For both concrete and steel, thermal properties such as thermal conductivity and heat capacity are highly temperature dependent. Different types of steel and concrete possess different thermal properties, which affect the distribution of temperature field. Fig. 10 (a) and (c) present the thermal properties of steel defined by Euro Code $4^{[1]}$, Chinese code "Technical code for concrete filled steel tubular structures"(GB50936) ${ }^{[38]}$ and Chinese code "Code for fire safety of steel structures in buildings"(GB51249) ${ }^{[41]}$. Fig. 10 (b) and (d) are the thermal properties of concrete defined by Euro Code 4, GB50936-2014 and GB51249-2017 respectively. It is worth noting that there are two types of concrete defined in Euro Code 4, i.e. the concrete with calcareous aggregates (EC4-Ca) and the concrete with siliceous aggregates (EC4-Si), . 


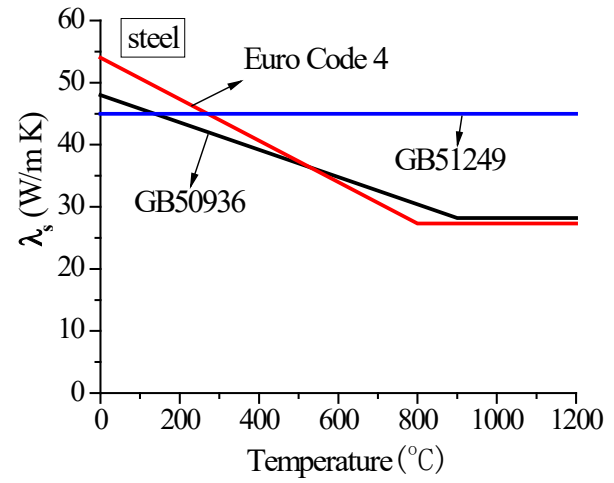

a) Thermal conductivity of steel

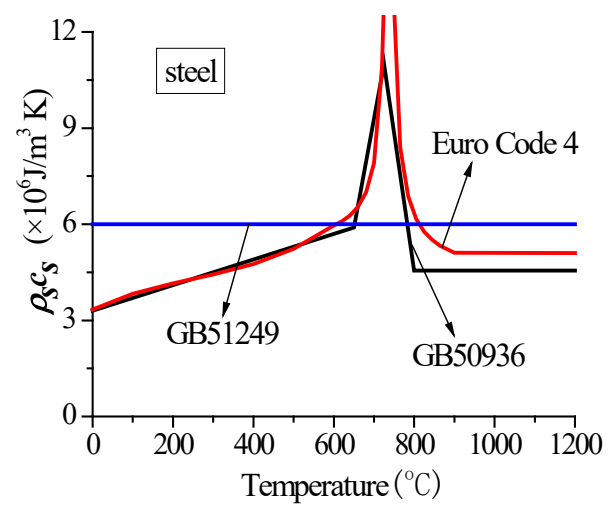

c) Heat capacity of steel

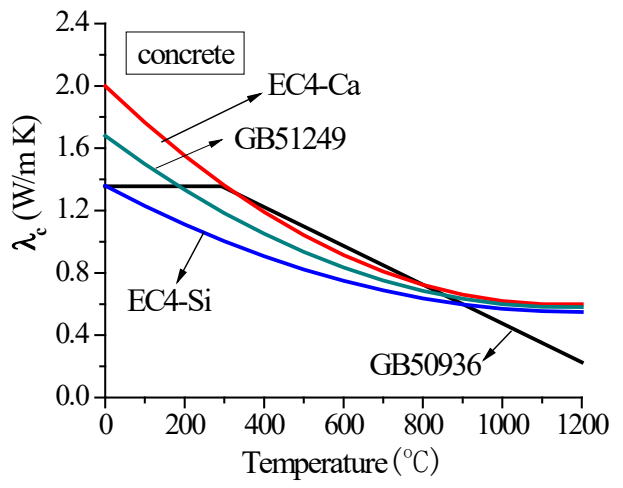

b) Thermal conductivity of concrete

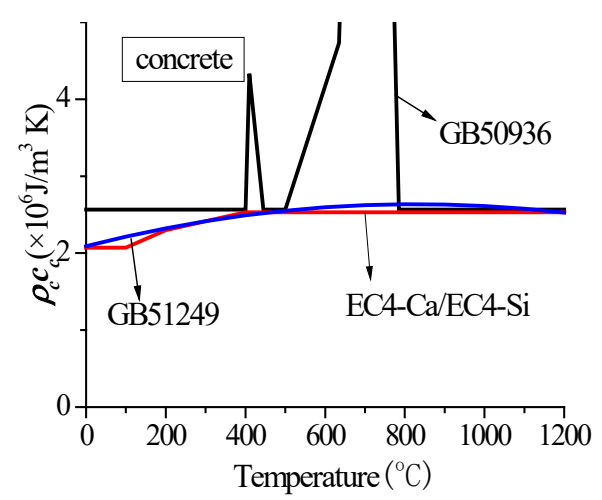

d) Heat capacity of concrete

Fig. 10 Thermal properties of steel and concrete defined by Euro Code 4 and Lie

Fig. 11 shows the average temperature of the representative hollow CFST columns mentioned in Section 2.3 with different combinations of materials suggested by the above two methods, including

Case 1: steel and concrete (from GB50936);

Case 2: steel and concrete (from GB51249);

Case 3: steel and concrete with calcareous aggregates from Euro Code 4;

Case 4: steel and concrete with siliceous aggregates from Euro Code 4;

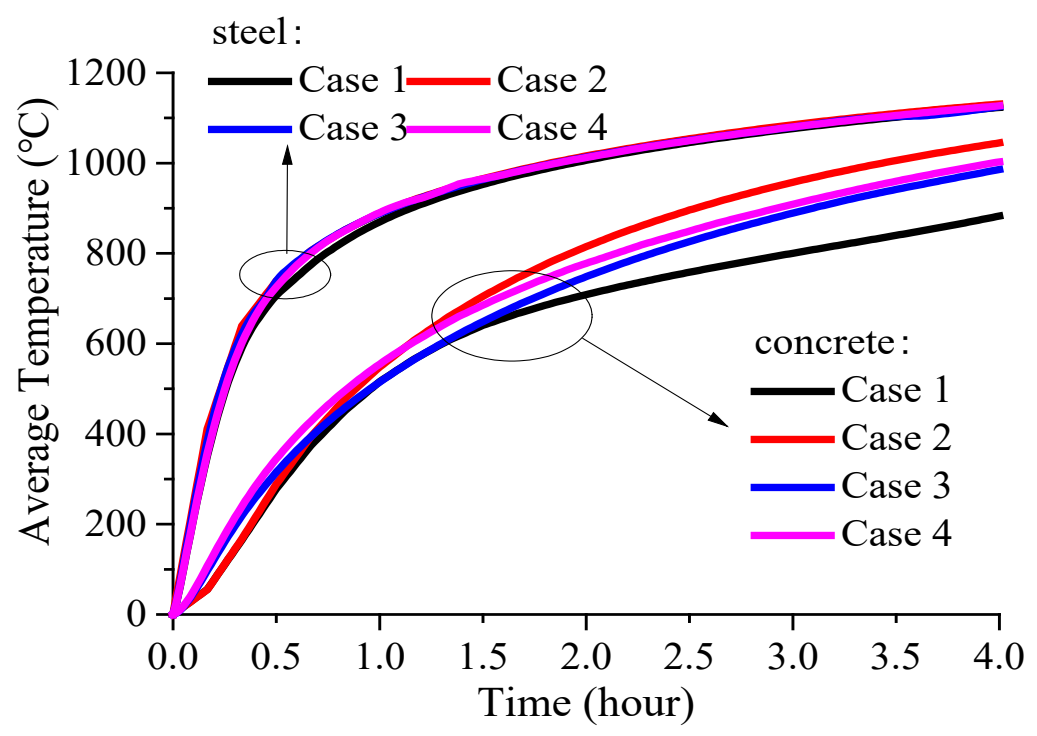

Fig. 11 Aaverage temperature of the hollow CFST column with different materials 
It can be learned from Fig. 11 that the average temperature of the CFST columns with different steel and concrete are generally different. For steel, since the curves are extremely close to each other, the effect of the materials can be neglected, while for concrete this effect must be considered. Generally speaking, at a given time, Case 1 (GB50936's concrete) has the lowest average temperature, while the concrete with thermal properties defined by GB51249 (Case 2) has the highest average temperature.

\subsection{Average temperature of unprotected CFST columns}

In the authors' previous research ${ }^{[33]}$, a simplified method was proposed to calculate average temperature of the steel and the concrete in a CFST column, as shown in Eq. (24) and (25).

$$
\begin{gathered}
\bar{\theta}_{s}=\bar{T}_{s}-T_{0}=A_{1}\left(1-\frac{1}{1+\left(t / B_{1}\right)^{C}}\right) \\
\bar{\theta}_{c}=\bar{T}_{c}-T_{0}=\frac{2}{1+\sqrt{\psi}} A_{2}\left(1-\frac{1}{1+\left(t / B_{2}\right)^{C}}\right)
\end{gathered}
$$

where $A_{1}=1200, B_{1}=0.337+8.5 \bar{d}, C=0.996+14 \bar{d}, A_{2}=120+1080 e^{-4.47 \bar{L}}, B_{2}=0.337+8.5 \bar{d}+$ $30 \bar{L}\left(\bar{L}^{2}-1.46 \bar{L}+0.64\right) ; t$ is the fire exposure time in hours; $\bar{d}$ is the equivalent thickness of steel in meters, $\bar{d}=\sqrt{\left(A_{c}+A_{k}+A_{s}\right) / \pi}-\sqrt{\left(A_{c}+A_{k}\right) / \pi} ; \bar{L}$ is the equivalent thickness of concrete in meters, $\bar{L}=$ $\sqrt{\left(A_{c}+A_{k}\right) / \pi}-\sqrt{A_{k} / \pi} ; \psi$ is the hollow ratio, $\psi=A_{k} /\left(A_{c}+A_{k}\right) ; A_{c}, A_{s}$ and $A_{k}$ are the cross sectional areas of steel, concrete and the hollow part, respectively, as illustrated in Fig. 3. The simple equations are effective, but there is no physical interpretations behind the method. For example, the equations cannot simply ensure that the temperature of the steel should be lower than the temperature of fire and the temperature of the concrete should be lower than the temperature of the steel. In addition, the method was developed using the thermal properties of concrete defined in the Chinese code GB50936-2014 and the equations are not applicable to other type of concrete with different thermal properties.

In this section, new research on calculating average temperature of unprotected CFST columns is presented. According to the analysis in Sections 3.1 and 3.2, the effect of cross-sectional shape can be ignored and a polygonal cross section may be transformed into its equivalent circular cross section in calculating average temperature. The effect of thermal properties, especially the thermal properties of concrete, should be considered in the calculation.

In order to propose a simple calculation method, the numerical results of the unprotected CFST columns in Section 2.3 are used as benchmarks. The columns are specified by the following numbering system using the index numbers in Table 1. All columns are defined by three numbers chosen from 1-6 as listed in Table 1. The first, second and third numbers are, respectively associated with a column's diameter, thickness of steel tube and hollow ratio. For example, No.123 represents the column with $100 \mathrm{~mm}$ in diameter, $5 \mathrm{~mm}$ in thickness of steel tube and 0.30 in hollow ratio. Inspired by the formulas proposed by other researchers ${ }^{[42]}$, new simplified formulas for calculating average temperature in steel and concrete are proposed as follows.

$$
\bar{\theta}_{\mathrm{s}}=\bar{T}_{s}-T_{0}=\eta_{s} \theta_{f}=\frac{(\mathrm{m} t)^{A_{s}}}{(\mathrm{~m} t)^{A_{s}}+B_{s}} \theta_{f}
$$




$$
\bar{\theta}_{\mathrm{c}}=\bar{T}_{c}-T_{0}=\eta_{c} \bar{\theta}_{s}=\frac{\left(n t_{w}\right)^{A_{c}}}{\left(n t_{w}\right)^{A_{c}}+B_{c}} \bar{\theta}_{s}
$$

In Eq. (26), $\bar{\theta}_{s}$ is the elevated average temperature of the steel tube; $\theta_{f}$ represents the elevated temperature of fire, which is defined as $\theta_{f}=345 \log _{10}(8 t+1)$ by ISO-834 and $\theta_{f}=1166-532 \cdot \exp (-0.01 t)+186$. $\exp (-0.05 t)-820 \cdot \exp (-0.2 t)$ by ASTME119; $\eta_{s}$ is the temperature ratio of $\bar{\theta}_{s}$ and $\theta_{f}$ relating the temperature of steel to the surrounding fire; $A_{s}=1+0.03 d_{s}$ and $B_{s}=0.032\left(d_{s}+20\right)$, where $d_{s}$ is the thickness of steel tube in millimetre (for polygonal cross section $d_{s}$ is the equivalent thickness); $t$ denotes the time of fire in hour; $m$ is a parameter relating to the type of concrete ( $m=1$ for GB51249, $m=0.93$ for GB50936, $m=0.95$ for EC4-Si and $m=1.07$ for EC4-Ca). In Eq. (27), $\bar{\theta}_{c}(t)$ refers to the elevated average temperature of concrete; $\eta_{c}$ is the temperature ratio of $\bar{\theta}_{c}$ and $\bar{\theta}_{s}$ relating the temperature of the concrete core to the temperature of steel; $A_{c}=0.67(1-0.1 \Psi)$ and $B_{c}=0.0016+0.005 \Psi$, where $\Psi$ is the hollow ratio of the CFST; $t_{w}$ is defined as $t_{w}=t /(b-a)^{2}$ where $b$ is the external radius of the concrete in millimetre (for polygonal cross section $b$ is the equivalent external radius) and $a$ represents the hollow radius in millimetre; $n$ is a parameter relating to the type of concrete (for GB51249, $n=1$; for GB50936, $n=0.79$; for EC4-Si, $n=1.04$ and for EC4-Ca, $n=0.81$ ).

Without loss of generality, only part of the comparisons are presented in Fig. 12 and their statistical analyses are listed in Table 2, which demonstrates that the simplified equations can be used to calculate the average temperature of unprotected CFST columns under fire.

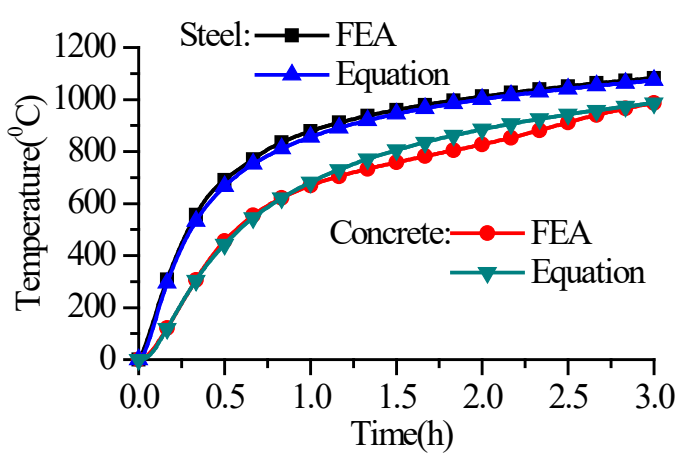

1) No. 123

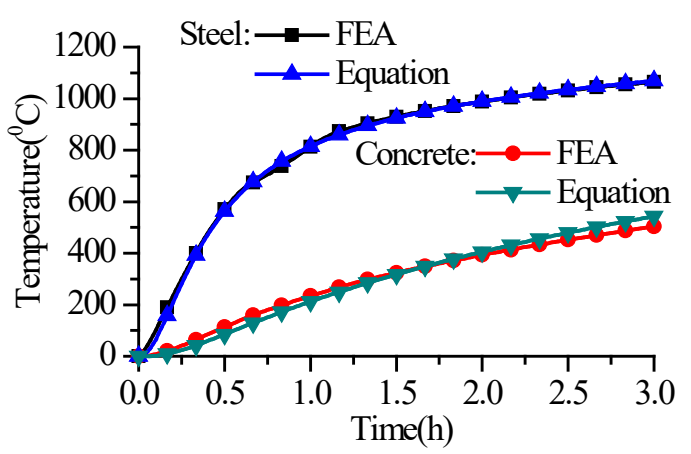

3) No. 362

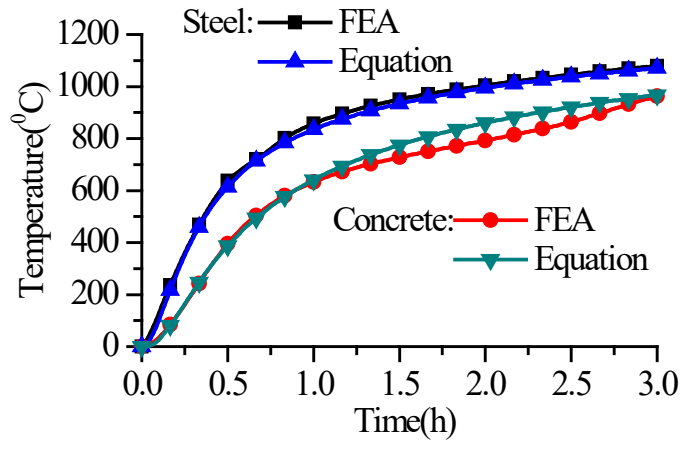

2) No. 246

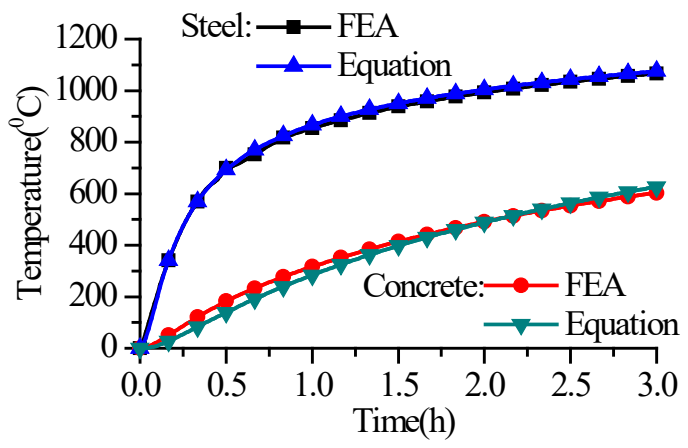

4) No. 415 


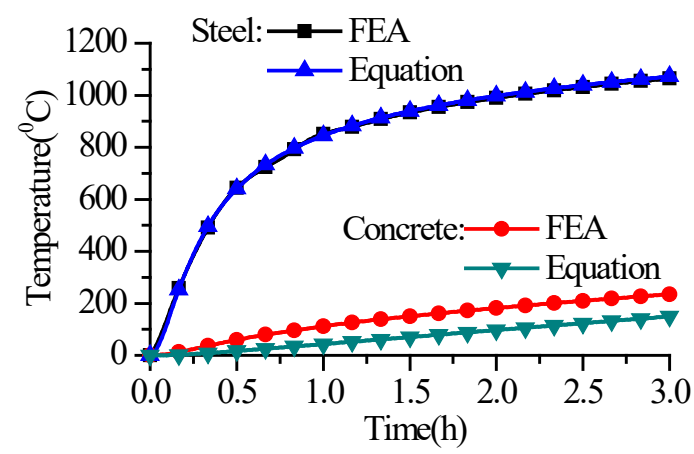

5) No. 531

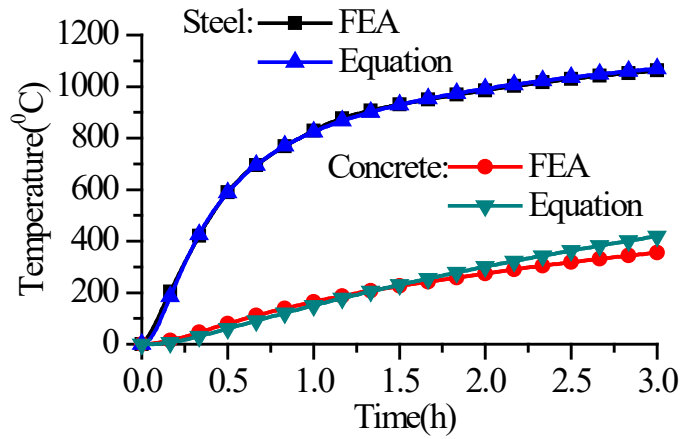

6) No. 654

Fig. 12 Formula and FEA results of average temperature for EC4-Ca

Further evaluations are made through comparisons between the newly proposed formulas (Eq. (26) and (27)), the formulas from the previous work (Eq. (24) and (25)) and the benchmark FEA results. Fig. 13 shows only one representative case, and a detailed analysis of the comparisons is shown in Table 2.

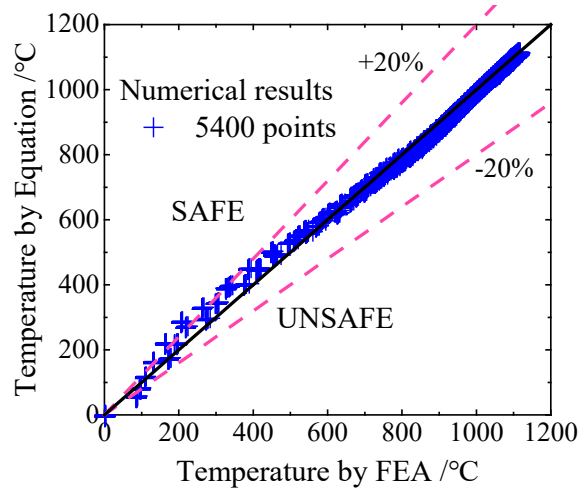

1) Temperature of steel by the new formula

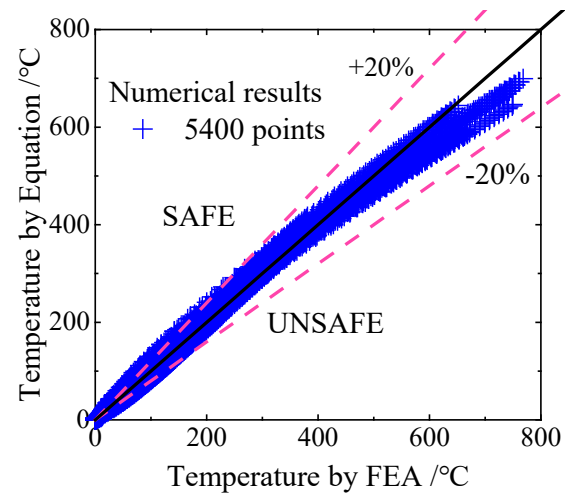

3) Temperature of concrete by the new formula

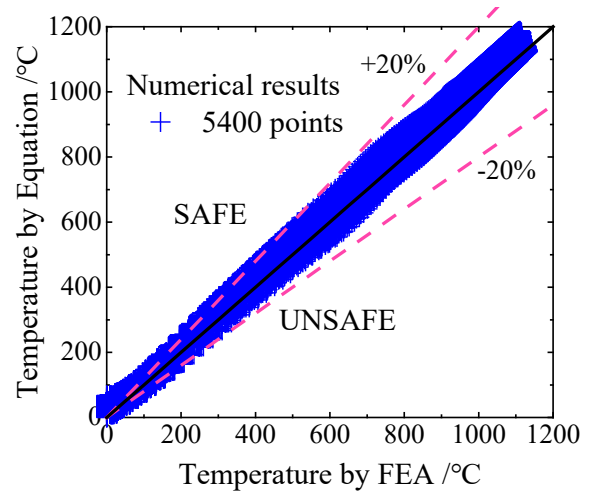

2) Temperature of steel by previous work's formula

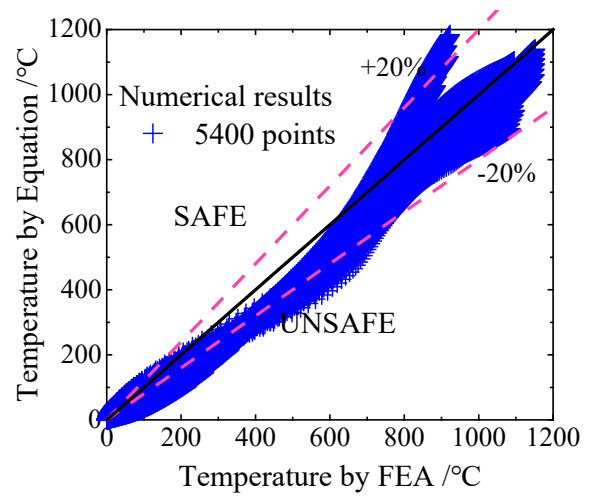

4) Temperature of concrete by previous formula

Fig. 13 Comparisons between the two methods on average temperature for EC4-Ca

Table 2 Comparison between new method and old method

\begin{tabular}{cccccc}
\hline \multirow{2}{*}{ Material } & \multicolumn{2}{c}{ Concrete Type } & & New equations & \multicolumn{2}{c}{$\bar{\theta}_{\text {Equation }} / \bar{\theta}_{F E A}$} \\
& & Mean & Variance & Mean & Variance \\
\hline \multirow{2}{*}{ Steel } & GB50936 & 1.02 & 0.005 & 1.04 & 0.015 \\
& GB51249 & 1.02 & 0.008 & 1.03 & 0.026
\end{tabular}




\begin{tabular}{cccccc} 
& EC4-Ca & 1.02 & 0.006 & 1.01 & 0.013 \\
& EC4-Si & 1.02 & 0.005 & 1.03 & 0.017 \\
\multirow{3}{*}{ Concrete } & GB50936 & 1.00 & 0.011 & 1.09 & 0.085 \\
& GB51249 & 1.05 & 0.011 & 1.03 & 0.104 \\
& EC4-Ca & 1.00 & 0.012 & 1.06 & 0.078 \\
& EC4-Si & 1.01 & 0.011 & 0.98 & 0.058
\end{tabular}

For the steel tubes, the results from both this paper and the previous work are all in good agreement with the numerical results, while the results from the equations proposed in this paper have a reduced variance. For the concrete, the results from the new equations are closer to the finite element analysis results and the variance is also smaller. In generally, most of the results given by the formulas proposed in this paper are more accurate.

\subsection{Average temperature of protected CFST columns}

Using the above validated simple temperature calculation method of unprotected CFST columns, the effect of protective coating on the average temperature is considered in this Section. By following the same approach as used in Section 3.3, the parameters of CFST columns presented in Section 2.3 are also adopted here. Before moving to the next step, the relation between the average temperature of the steel tube and that of the concrete are investigated first. It is assumed that although the average temperature of steel and the concrete will drop significantly due to the existence of protective coating, the ratio of the average temperature of concrete and that of steel tube remains constant, i.e. the temperature ratio $\eta_{c}=\bar{\theta}_{c} / \bar{\theta}_{s}$ is constant at any given time regardless of the thickness of the protective coating. To verify this, taking the case shown in Fig. 12 as an example, the average temperature of the CFST column with various thickness of heat-barrier coating is computed and the $\eta_{c}$-time curves are plotted in Fig. 14. It can be seen from Fig. 14 that the curves for various coating thickness are very close to each other, which means that the thickness of coating has insignificant effect on $\eta_{c}$.

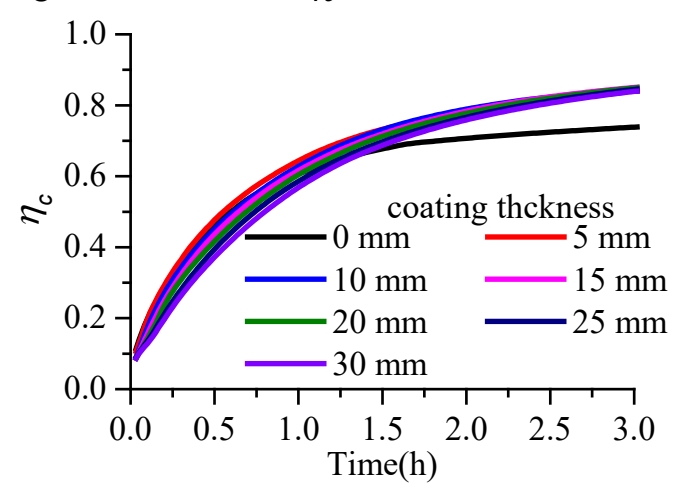

1) No. 123

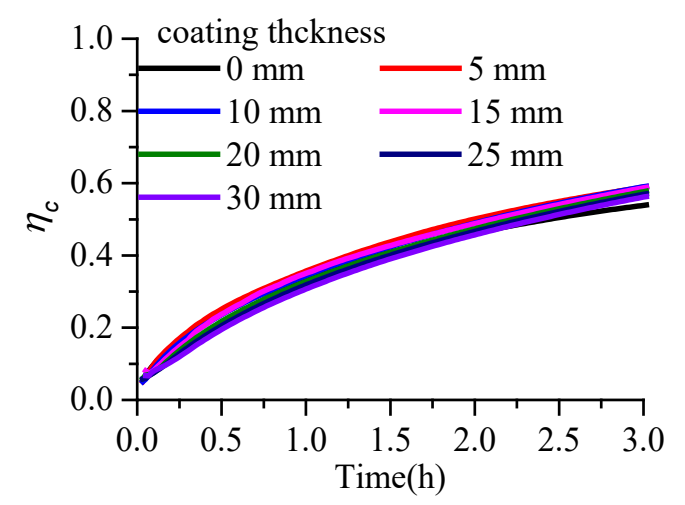

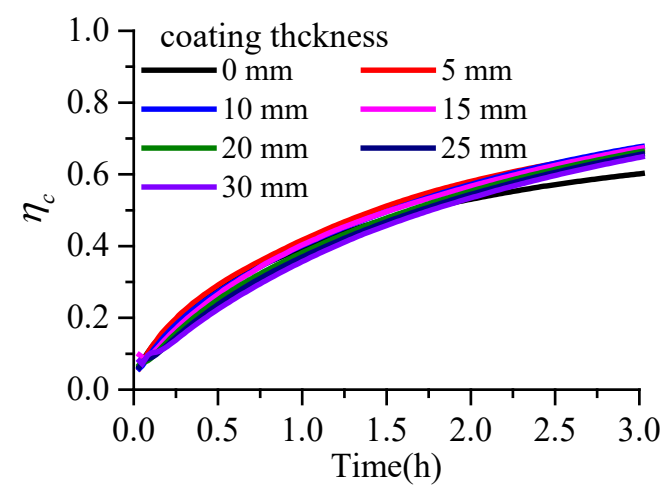

2) No. 246

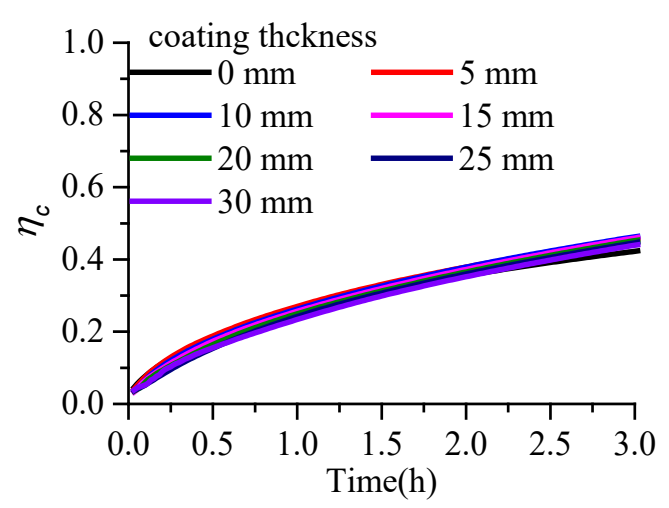


3) No. 362

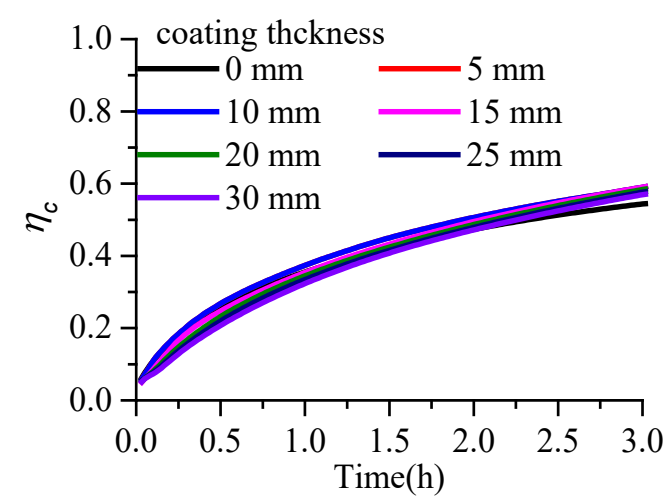

5) No. 531
4) No. 415

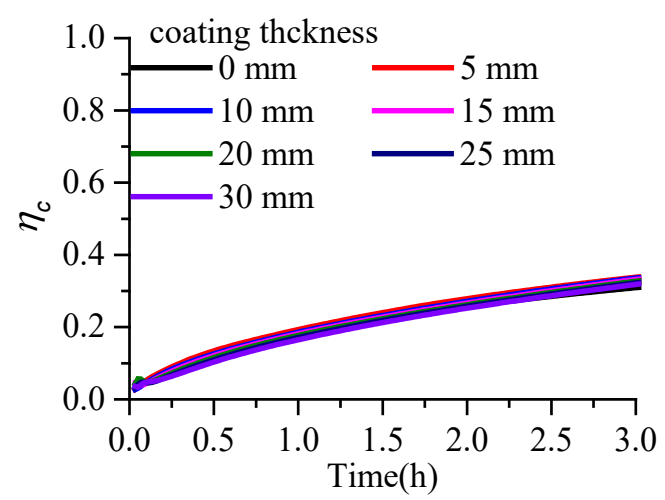

6) No. 654

Fig. 14 Temperature ratio of concrete $\eta_{c}$-time curves for different cases

Hence, as long as the average temperature of the steel tube covered by protective coating is obtained, the average temperature of the concrete core can be readily calculated by Eq. (27). In order to compute the average temperature of the protected steel tube, the temperature ratio, $\eta_{s}$, should be evaluated first. According to Eq. (26), $\eta_{s}=$ $(m t)^{A_{s}} /\left((m t)^{A_{s}}+B_{s}\right)$, where $m$ is a parameter relating to the type of concrete, $A_{s}$ and $B_{s}$ are the two constants to be determined. For steel structures, it is found that the thermal insulation effect is highly associated with the thermal conductivity, $\lambda_{p}$, as well as the thickness, $d_{p}$, of the heat-protective coating ${ }^{[41]}$. Therefore, it is reasonable to assume that $A_{s}$ and $B_{s}$ should be related to the type and the thickness of protective coating. Both specialist fireproof material and cement mortal are used as protective coating materials in the numerical simulation. The thermal properties of the specialist fireproof material are stated in Section 2.2 and the thermal properties of the cement can be found in $\mathrm{Han}^{[14]}$. After curve fitting the numerical results of CFST columns with $0 \mathrm{~mm}, 5 \mathrm{~mm}, 10 \mathrm{~mm}, 20 \mathrm{~mm}$ and $40 \mathrm{~mm}$ thick protective coating, $A_{s}$ and $B_{S}$ are in the form shown in Eqs. (28) and (29), respectively.

$$
\begin{gathered}
A_{s}=0.003\left(9 e^{-d_{p} / \lambda_{p}}+1\right) d_{s}+1 \\
B_{s}=\left(3 \times 10^{-5} \frac{d_{p}^{2}}{\lambda_{p}}+0.001 \frac{d_{p}}{\lambda_{p}}+0.0032\right) \cdot\left(d_{s}+20\right)
\end{gathered}
$$

It is worth noting that Eq. (28) and (29) are also applicable to calculate the factors for CFST columns without protection, i.e. when $d_{p}=0$. The comparisons are made between the numerical results and the results calculated from the new formulas, i.e., Eqs. (26) to (29). The comparisons for both the steel tube and the concrete are shown in Fig. 15. 


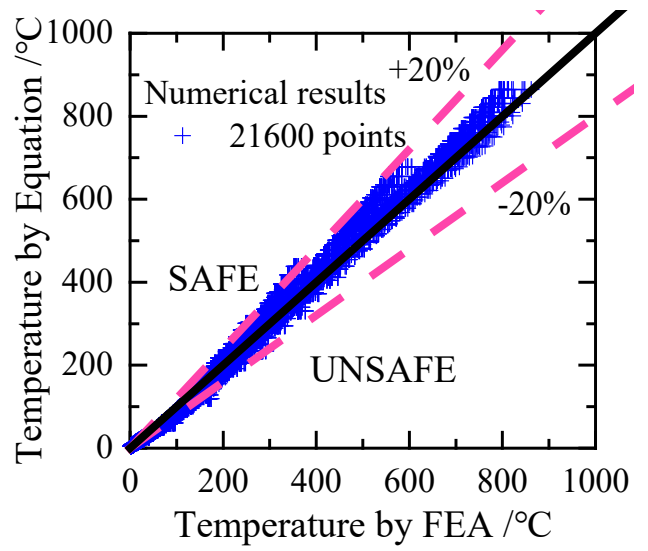

a) CFST columns with fireproof coating, steel tube

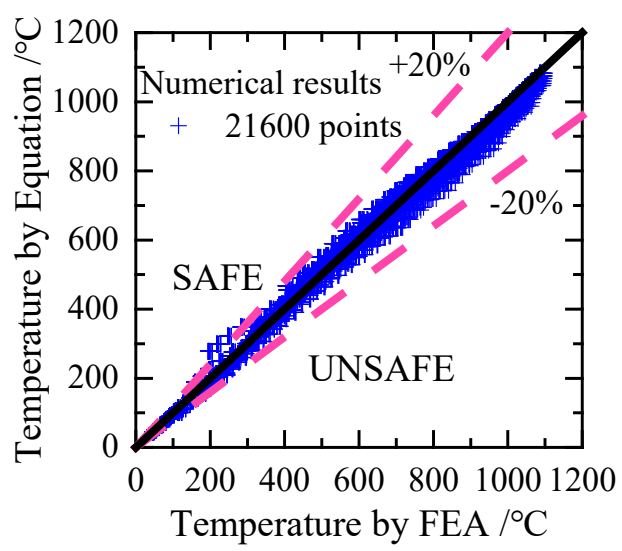

c) CFST columns with cement coating, steel tube

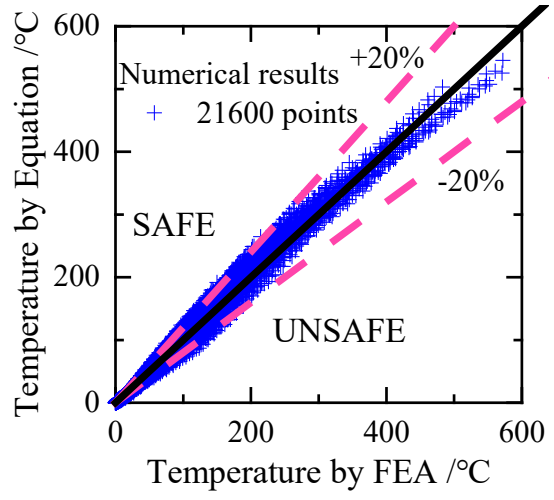

b) CFST columns with fireproof coating, concrete

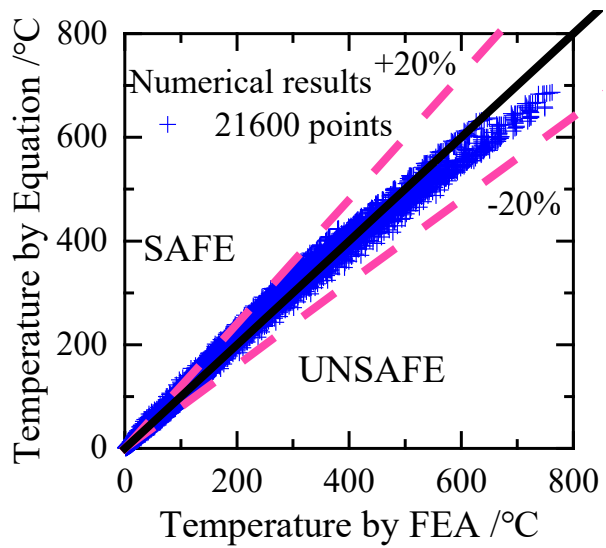

d) CFST columns with cement coating, concrete

Fig. 15 Comparison between the from FEA and the new equations

A statistic evaluation of the results presented in Fig. 15 shows that for the steel tube of CFST columns with fireproof coating, the mean value of the ratio between the analytical and numerical results is 0.98 and the variance is 0.023 . For the concrete, the mean value is 0.98 and the variance is 0.036 . As for CFST columns with cement mortar, the average ratio of steel tube and concrete is 1.00 and 1.04 respectively; the variance of steel tube and concrete is 0.003 and 0.009 respectively. Therefore, it can be concluded that the simple method using the new equations with the new reduction factors is valid in predicting the average temperature of CFST columns with heat-protective coating.

\section{Comparison and analysis of the unified calculation method}

\subsection{CFST columns without protection}

\subsubsection{Comparisons with existing experimental data}

With the newly proposed equations for calculating average temperature, the fire resistance of CFST columns with or without protective coating is computed by following procedure stated in Section 2. Furthermore, experimental data from 69 circular and 61 square CFST columns without protective coating ${ }^{[7,11,28,30,43,44]}$ are collected to validate the new method. In a practical situation, a CFST column is inevitably subjected to combined loadings, e.g., subjected to eccentric compression that causes both compression and bending on the cross-sections of the column. Hence, the fire resistance of CFST columns under eccentric loading are also studied, where experimental results from 19 circular and 21 square CFST columns ${ }^{[7,11,28,30,43,44]}$ are collected for comparisons. The equivalent reduction factors derived 
from Euro Code 4 are adopted in the calculations.

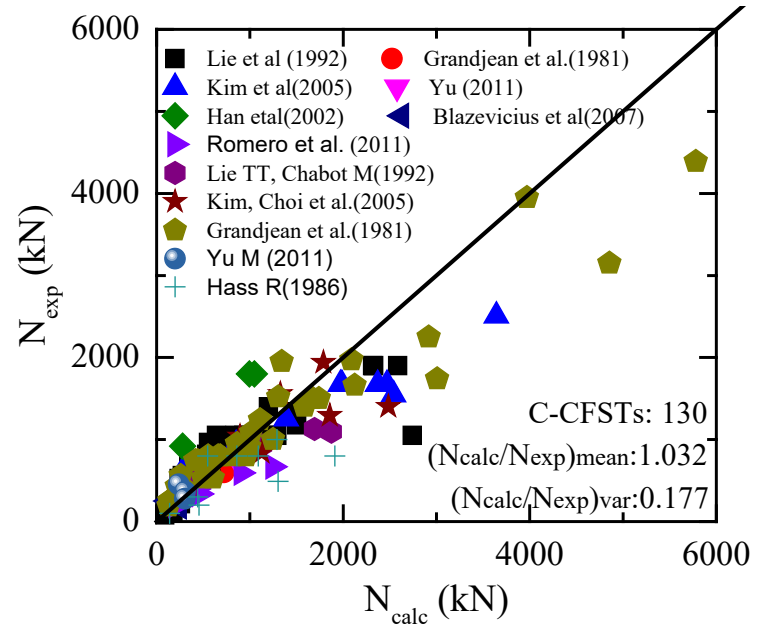

a) CFST columns under axial loading

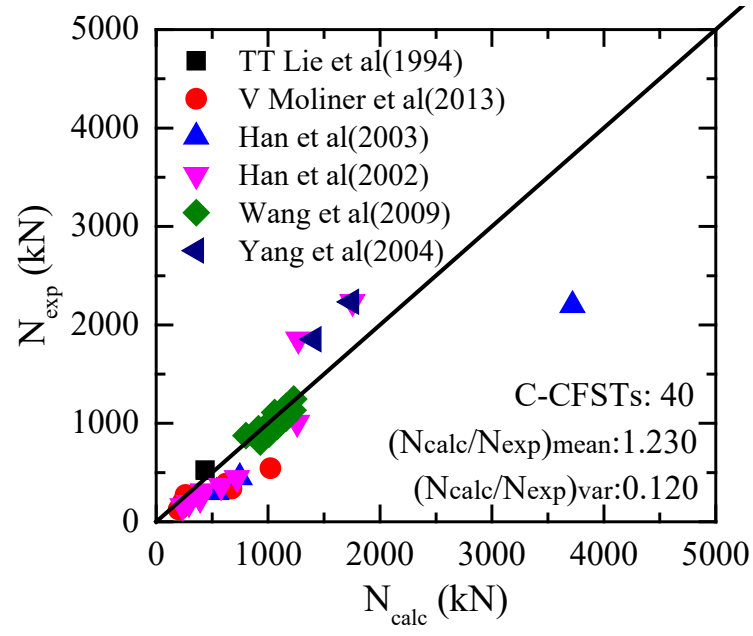

a) CFST columns under eccentric loading

Fig. 16 Comparison between the unified calculation method and experimental data

In Fig. 16, $N_{\text {calc }}$ refers to the axial force obtained from the unified method while $N_{\text {exp }}$ refers to the axial force obtained from the experiments. It can be estimated from Fig. 16 that the average ratio of the calculation results to the experimental data for the CFST columns under axial loading is 1.032 , with a variance of 0.177 , while the average ratio under eccentric loading is 1.230 with a variance of 0.120 . Clearly, there is a strong correlation between the predictions of the formulas and the experimental results, which suggests that the prediction equations are satisfactorily accurate. In conclusion, this unified method can predict the fire resistance of CFST columns under combined axial compression and bending well.

\subsubsection{Comparison with existing calculation methods}

From the theories and calculation shown above, it is evident that the equivalent reduction factors have significant impact on the predictions from the equations. In fact, the equivalent reduction factors can be derived from various methods of material reduction factors presented in design $\operatorname{codes}^{[1,14,38,41]}$. In fact, the reduction factors in these codes are originated from different experiments conducted by previous scholars. Due to different mix proportion of concrete as well as the variability of concrete, the results may vary from each other significantly. In this section, without losing of generality, the unified method is incorporated with three different sets of equivalent reduction factors derived from Euro Code $4^{[1]}$ (UM-EC4 for short), the Chinese code for steel structures GB512492017 $7^{[41]}$ (UM-GB51249 for short), Han's work ${ }^{[14]}$ (UM-Han for short) and the Chinese code for CFST structures GB50936-2014 ${ }^{[38]}$ (UM-GB50936 for short), respectively, in order to assess their suitability to be adopted in design.

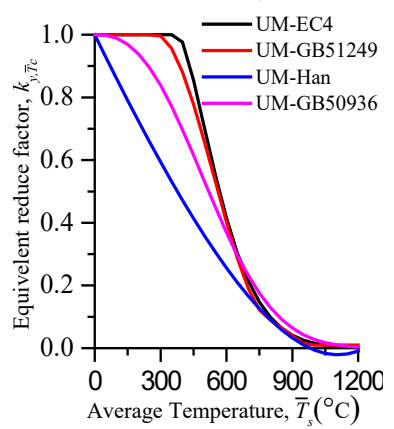

a) $k_{y, \bar{T}_{s}}$

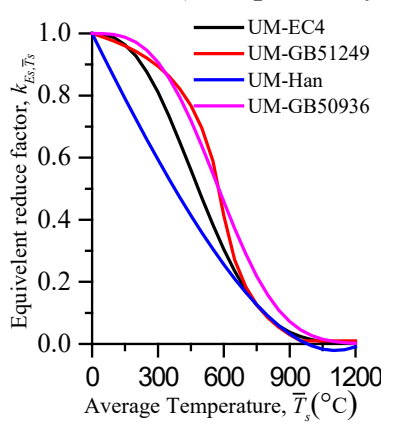

b) $k_{E_{s}, \bar{T}_{S}}$

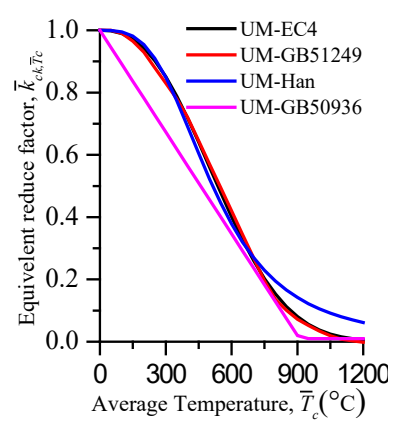

c) $\bar{k}_{c k, \bar{T}_{c}}$

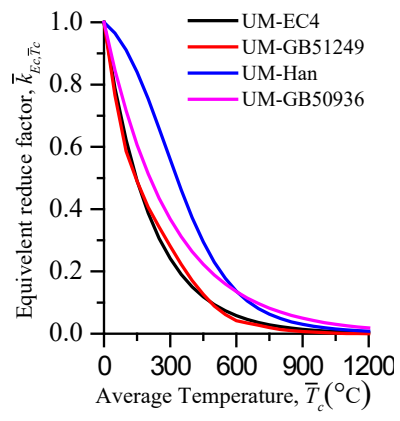

d) $\bar{k}_{E_{c}, \bar{T}_{c}}$

Fig. 17 Equivalent reduction factors from different methods 
Fig. 17 presents the four reduction factors, i.e. $k_{y, \bar{T}_{S}}, k_{E_{S}, \bar{T}_{S}}, \bar{k}_{c k, \bar{T}_{c}}$ and $\bar{k}_{E_{c}, \bar{T}_{c}}$, as functions of the average temperature. For $k_{y, \bar{T}_{s}}$, Fig. 17(a) shows that the equivalent reduction factors derived from Han's work are the smallest; the curves of UM-EC4 and UM-GB51249 are almost identical. In Fig. 17(b) the smallest $k_{E_{S}, \bar{T}_{S}}$ is also from UM-Han. When the average temperature is lower than $600^{\circ} \mathrm{C}$, the reduction factors derived from GB512492017 are close to those of UM-GB50936, while when the average temperature exceeds $600^{\circ} \mathrm{C}$, there are no significant differences between the four curves. Fig. 17(c) shows that the $\bar{k}_{c k, \bar{T}_{c}}$ from UM-GB50936 is the lowest of the four. The results from other three methods are approximately the same across the temperature range. For $\bar{k}_{E_{c}, \bar{T}_{c}}$, the equivalent reduction factors based on Euro Code 4 and GB51249-2017 are approximately the same.

Apart from the reduction factors, other researchers have also established ${ }^{[14,26,29,31]}$ a number of calculation methods regarding axially loaded CFST columns at elevated temperature. The calculation equations from most of the methods can be briefly presented in the form shown in Eq. (32) and Eq. (33).

$$
\begin{aligned}
& N_{u, T}=k_{1} N_{u, 0} \\
& N_{0, T}=k_{2} N_{0,0}
\end{aligned}
$$

In Eq. (30) and Eq. (31), $N_{u, T}$ and $N_{u, 0}$ refer to the plastic resistance of a CFST column at elevated temperature and at ambient temperature, respectively, after considering the buckling effect; $N_{0, T}$, and $N_{0,0}$ are the respective plastic resistance of the CFST the column at elevated temperature and ambient temperature without considering buckling; $k_{1}$ and $k_{2}$ are the associated temperature reduction factors.

Results obtained from some representative calculation methods are included in the comparisons, which include the methods proposed by A Espinos et $\mathrm{al}^{[31]}$, LH Han ${ }^{[14]}$, KH Tan and CY Tang ${ }^{[29]}$ and YC Wang ${ }^{[26]}$. It is worth noting that Espinos and Wang did not state clearly whether their methods were capable of predicting the mechanical behavior of square CFST columns. In this Section, comparisons are made, respectively, for circular and square cross-sections. Fig. 18 shows the factors, $k_{1}$ and $k_{2}$, obtained from the method proposed in this paper using four different sets of equivalent reduction factors, which are compared with the results from the above mentioned previous research.

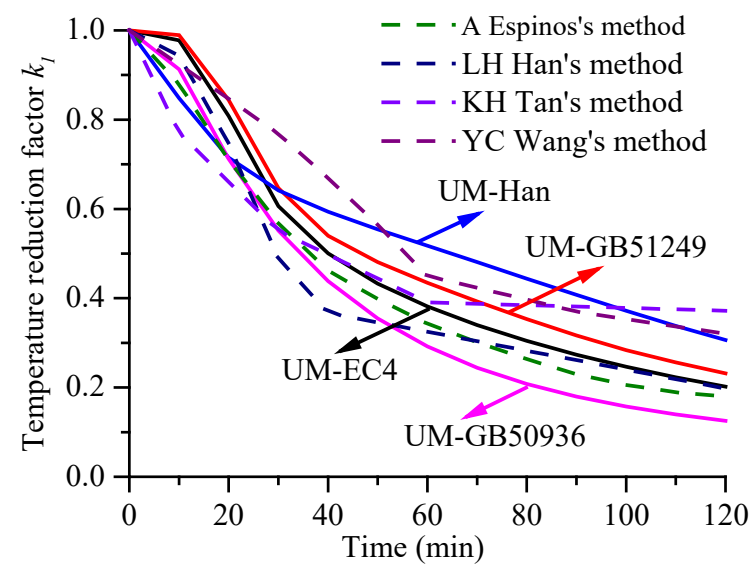

a) $k_{1}$ for circular cross section

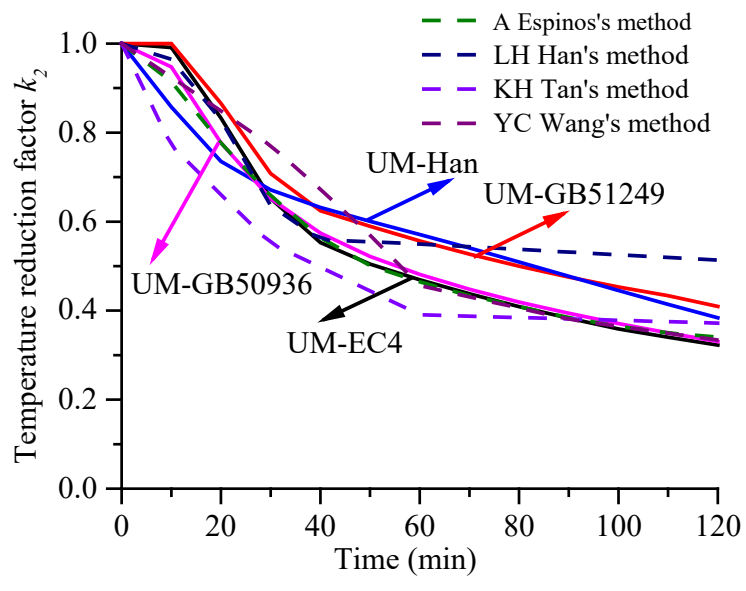

b) $k_{2}$ for circular cross section 


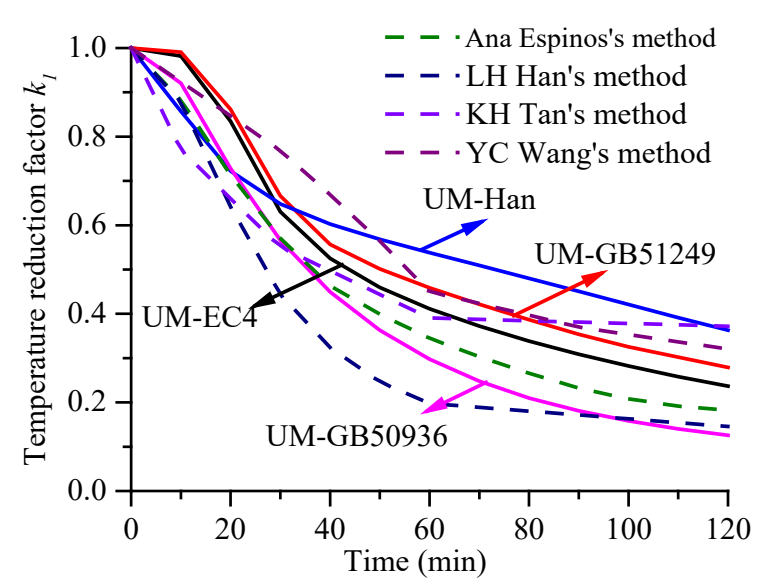

c) $k_{1}$ for square cross section

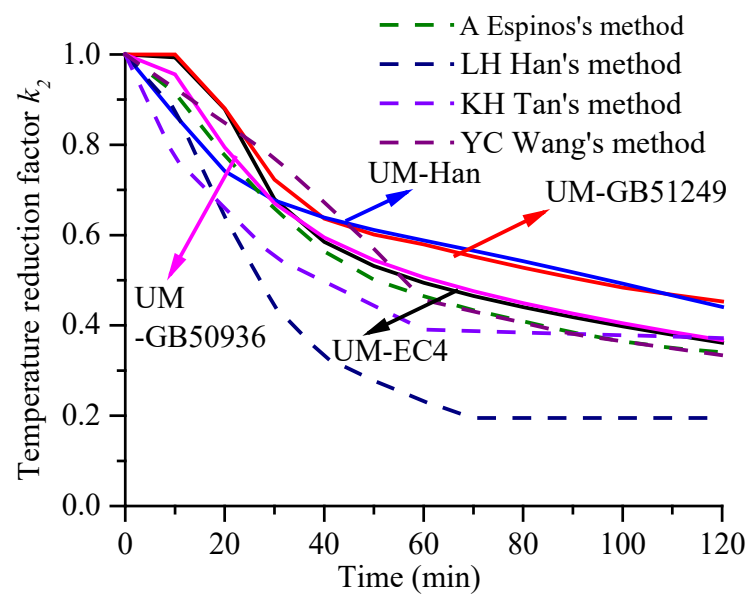

d) $k_{2}$ for square cross section

Fig. 18 Temperature reduction factors from different methods

It can be learned from Fig. 18 that in general the predictions from various methods are more comparable for circular than square sections. It is evident that Han's method is more conservative than others are. With different sets of the equivalent reduction factors, the curves of $k_{1}$ and $k_{2}$ vary significantly. Although the UM-GB51249 and UMEC4 curves are much closer to each other in Fig. 17, the slight discrepancies in the equivalent reduction factors have resulted in significant differences in $k_{1}$ and $k_{2}$, as shown in Fig. 18. Fig. 17 also shows that by choosing different equivalent reduction factors, the time dependent $k_{1}$ and $k_{2}$ calculated from the unified formulas are generally in line with those obtained from other commonly used theories, which suggests that by choosing proper time dependent $k_{1}$ and $k_{2}$ curves, the unified equations can reproduce the temperature reduction factors from the above-discussed existing theories.

\subsection{CFST columns with protection}

On the basis of the previous sections, the predictions from the new equations proposed in this paper are compared with available experimental data ${ }^{[45,46]}$ in Fig. 19. The four different sets of equivalent reduction factors (material) discussed in Fig. 17 are used in the calculations

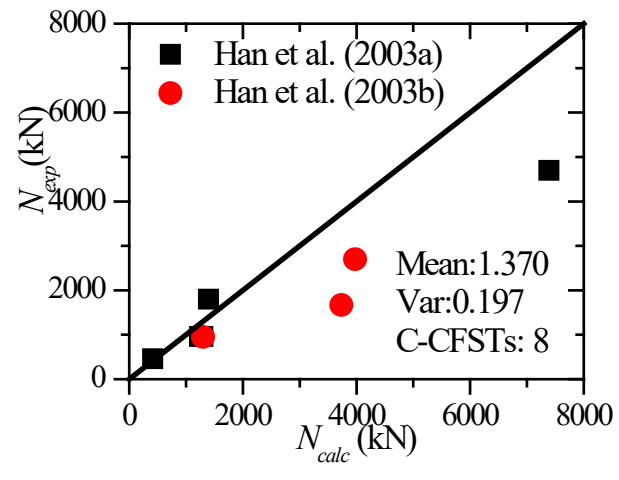

a) UM-EC4

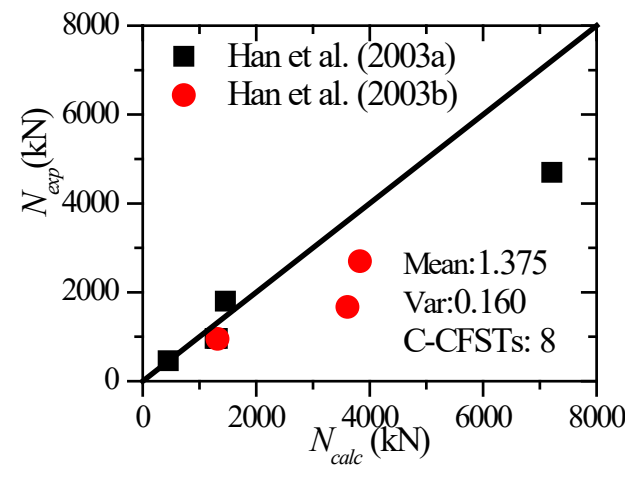

b) UM-GB51249 


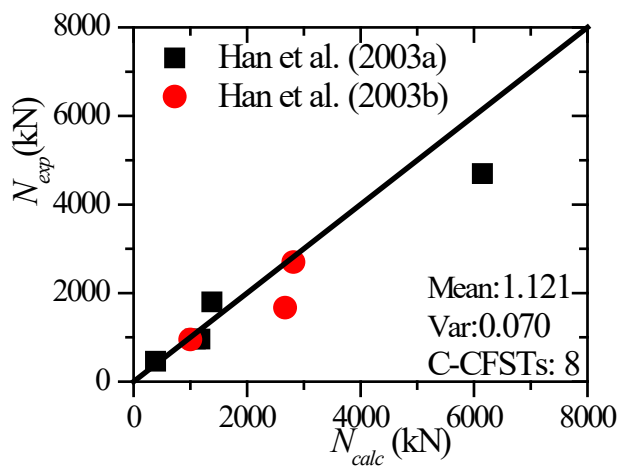

c) UM-Han

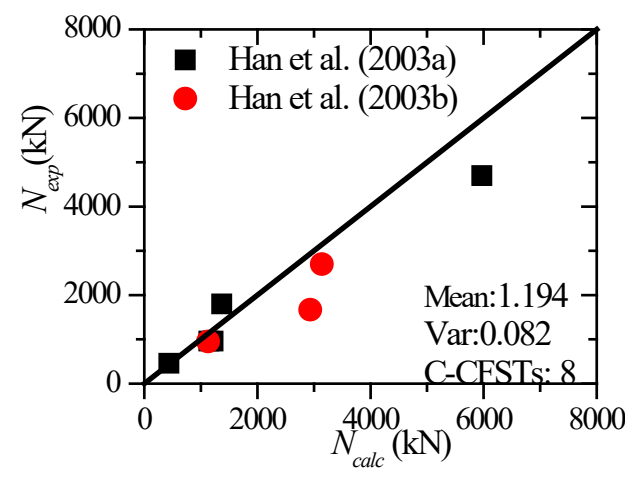

d) UM-GB50936

Fig. 19 Comparison regarding protected axially loaded CFST columns

A statistical analysis of the results presented in Fig. 19 shows that the average ratios of the analytical predictions, which are calculated from the four sets of equivalent reduction factors, to the experimental result are, respectively, $1.370,1.375,1.121$ and 1.194 , with their respective variances of $0.197,0.160,0.070$ and 0.082 . The first two average ratios (1.37 and 1.375) indicate that the fire resistance prediction are overestimated, suggesting that the effect of material deterioration due to the elevated temperature might be underestimated in the calculation. As illustrated in Section 4.1 and in Fig. 18, when the duration of fire exposure is short ( $<20$ Minutes) and the average temperatures of both the steel tube and the concrete of the unprotected CFSTs are not high $\left(<750^{\circ} \mathrm{C}\right)$, the temperature reduction factor, $k_{1}$, obtained from UM-Han and UM-GB5093 is small. For the CFST with protections, the average temperatures of both the steel and the concrete are small all through the duration of fire exposure, which is similar to the initial heating stage of unprotected columns, thus the temperature coefficient $k_{1}$ obtained from UM-Han and UM-GB50936 is also small and lower than the ones from UM-EC4 and UM-GB51249. It is observed that the predictions of UM-Han and UM-GB50936 are more accurate than those of other two theories. This observation suggests that using a smaller (conservative) temperature reduction factor results in better comparisons with the experimental results.

\section{Concluding remarks}

This paper proposed a unified method for predicting fire resistance of CFST columns on the basis of calculating the average temperature of critical cross sections. A simplified method was also proposed to calculate the average temperature. The followings are the main conclusions.

1) The calculation method proposed previously by the authors for calculating fire resistance of unprotected CFST columns is extended and validated to include protected CFST columns, thus a unified calculation method was developed for both protected and unprotected CFST columns

2) It was found that the number of sides of a polygonal cross section had negligible influence on the average temperature, when comparing with the average temperature calculated from its equivalent circular cross section with the same cross sectional area and the same materials. As expected, the material thermal properties have significant effect on the average temperature of CFST members.

3) The simplified method developed in the paper for computing the average temperature of steel tube and the concrete core of a CFST column can be applied to CFST columns with and without heat-protective coating.

4) Further research is needed to conduct reliability analysis of CFST columns under fire, considering the randomness of mechanical behavior of CFST columns caused by the mesoscale structure of concrete core and manufacturing 
deficiencies.

\section{Acknowledgement}

The authors are grateful for the financial support from the National Natural Science Foundation of China (Grant No. 51878518 and No.51738011)

\section{Appendix}

\section{Unified calculation method for protected and unprotected CFST columns under fire}

a) Plastic resistance to axial compression

$$
N_{0, T}=f_{c k} \bar{k}_{c k, T} A_{c}+f_{y} \bar{k}_{y, T} A_{s}
$$

where $A_{c}$ and $A_{s}$ are the areas of concrete and steel; $f_{c k}$ and $f_{y}$ are the strengths of concrete and steel; $\bar{k}_{c k, T}$ and $\bar{k}_{y, T}$ are the equivalent strength reduction factors respectively.

b) Plastic resistance to axial tension

$$
N_{0 t, T}=-f_{y} \bar{k}_{y, T} A_{s}
$$

c) Ultimate bending moment

$$
M_{u, T}=\left(1-\frac{\xi_{T}}{4\left(\xi_{T}+1\right)}\right) f_{y} \bar{k}_{y, T} A_{s} \frac{D}{2}
$$

where $\xi_{T}$ denotes the confining coefficient under fire and is defined as $f_{y, \bar{T}_{s}} A_{s} / f_{c k, \bar{T}_{c}} A_{c}$. The strength of concrete at average temperature $\bar{T}_{c}$ can be determined by $f_{c k, \bar{T}_{c}}=\bar{k}_{c k, \bar{T}_{c}} f_{c k}$ and the strength of steel is equal to $f_{y \bar{T}_{s}}=k_{y \bar{T}_{s}} f_{y}$.

\section{d) Euler buckling load}

$$
N_{c r, T}=\frac{\pi^{2} E I_{s c, T}}{L_{0}^{2}}, E I_{s c, T}=E_{c} \bar{k}_{E_{c}, T} I_{c}+E_{s} \bar{k}_{E_{s}, T} I_{s}
$$

where $(E I)_{s c, T}$ is the effective stiffness under high temperature, which can be calculated by $(E I)_{s c, T}=E_{c} \bar{k}_{E_{c}, T} I_{c}+$ $E_{S} \bar{k}_{E_{S}, T} I_{S} ; E_{c}$ and $E_{S}$ are the elastic modulus of concrete and steel; $\bar{k}_{E_{c}, T}$ and $\bar{k}_{E_{S}, T}$ are the modulus reduction factors of concrete and steel; $I_{c}$ and $I_{S}$ are the inertial moments of concrete core cross section and steel tube cross section.

e) Stability factor

$$
\varphi_{s c, T}=\frac{1}{\Phi+\sqrt{\Phi^{2}-\lambda_{s c, T}^{2}}}
$$

where $\Phi=0.5\left[\lambda_{s c, T}^{2}+\alpha\left(\lambda_{s c, T}-0.2\right)+1\right] ; \lambda_{s c, T}=\sqrt{N_{0, T} / N_{c r, T}} ; \alpha$ is the imperfection factor and for buckling curve "c" defined in Euro Code $4 \alpha=0.49$.

f) Interaction equation

$$
\frac{\beta_{m} M}{M_{u, T}}=\left(1-\frac{N}{\varphi_{s c, T} N_{0, T}}\right)\left(1-\frac{\varphi_{s c, T} N}{N_{0 t, T}}\right)\left(1-\frac{\varphi_{s c, T} N}{N_{c r, T}}\right)
$$


where $\beta_{m}$ is the coefficient of equivalent bending moment, the value of which can be found in relevant design code ${ }^{[40]}$.

\section{References:}

[1] EN 1994-1-2:2005. Design of composite steel and concrete structures Part 1.2: General rules, structural fire design, Brussels. EN 1994-1-2:2005: British Standards Institution, 2005.

[2] DBJ13-51-2003. Technical specification for concrete-filled steel tubular structures. DBJ13-51-2003. Fuzhou: The Construction Department of Fujian Province, 2003.

[3] ASCE/SFPE 29 - 99. Standard calculation method for structural fire protection. ASCE/SFPE 29 - 99. Reston, USA: American Society of Civil Engineers, 1999.

[4] ACI Committee. Standard Method for determining fire resistance of concrete and masonry construction assemblies. ACI 216.1M-07. Detroit, USA: American Concrete Institute, 2007.

[5] Kodur VKR. Factors Affecting the Fire Resistance of Circular Hollow Steel Columns Filled with Steel-Fibre Reinforced Concrete.: NRC-CNRC Internal Report No. 598, Construction National Research Council Canada, 1996.

[6] Sakumoto Y, Okada T, Yoshida M, Tasaka S. Fire Resistance of Concrete-Filled, Fire-Resistant Steel-Tube Columns. J MATER CIVIL ENG. 1994;6(2): 169-84.

[7] Lie TT, Chabot M. Experimental Studies on the Fire Resistance of Hollow Steel Columns Filled with Plain Concrete.: NRC-CNRC Internal Report No. 611,Construction National Research Council Canada, 1992.

[8] Han LH, Xu L, Zhao XL. Tests and analysis on the temperature field within concrete filled steel tubes with or without protection subjected to a standard fire. ADV STRUCT ENG. 2003;6(2): 121-33.

[9] Han LH, Zhao XL, Yang YF, Feng JB. Experimental Study and Calculation of Fire Resistance of Concrete-Filled Hollow Steel Columns. J STRUCT ENG. 2003;129(3): 346-56.

[10] Kodur VKR. Design Equations for Evaluating Fire Resistance of SFRC-Filled HSS Columns. J STRUCT ENG. 1998;124(6): 671-7.

[11] Romero ML, Moliner V, Espinos A, Ibañez C, Hospitaler A. Fire behavior of axially loaded slender high strength concrete-filled tubular columns. J CONSTR STEEL RES. 2011;67(12): 1953-65.

[12] Lie TT, Chabot M. A Method To Predict the Fire Resistance of Circular Concrete Filled Hollow Steel Columns. Journal of Fire Protection Engineering. 1990;2: 111-24.

[13] Hong S, Varma AH. Behavior of CFT Beam-Columns under Elevated Temperatures from Fire Loading.: ASCE, 2005. 52. Pages.

[14] Han LH. Concrete-filled steel tubular structures——-theory and application(2nd Edtion). Beijing: Science press.

[15] Ding J, Wang YC. Realistic modelling of thermal and structural behaviour of unprotected concrete filled tubular columns in fire. J CONSTR STEEL RES. 2008;64(10): 1086-102.

[16] Espinos A, Romero ML, Hospitaler A. Advanced model for predicting the fire response of concrete filled tubular columns. J CONSTR STEEL RES. 2010;66(8-9): 1030-46.

[17] Yu M, Zha XX, Ye JQ, Li Y. Fire responses and resistance of concrete-filled steel tubular frame structures. INT J STRUCT STAB DY. 2010;10(2): 253-71.

[18] Lu H, Zhao X, Han L. FE modelling and fire resistance design of concrete filled double skin tubular columns. J CONSTR STEEL RES. 2011;67(11): 1733-48.

[19] Yang H, Liu F, Gardner L. Performance of concrete-filled RHS columns exposed to fire on 3 sides. ENG STRUCT. 2013;56: 1986-2004.

[20] Yao Y, Li H, Tan K. Theoretical and numerical analysis to concrete filled double skin steel tubular columns under fire conditions. THIN WALL STRUCT. 2016;98: 547-57. 
[21] Guo H, Long X, Yao Y. Fire resistance of concrete filled steel tube columns subjected to non-uniform heating. J CONSTR STEEL RES. 2017;128: 542-54.

[22] Ibañez C, Bisby L, Rush D, Romero ML, Hospitaler A. Post-heating response of concrete-filled steel tubular columns under sustained loads. Structures. 2019;21: 90-102.

[23] Aribert JM, Renaud C, Zhao B. Simplified fire design for composite hollow-section columns. Proceedings of the Institution of Civil Engineers - Structures and Buildings. 2008;161(6): 325-36.

[24] Kodur VKR. Performance of high strength concrete-filled steel columns exposed to fire. CAN J CIVIL ENG. 1998;25(6): 975-81.

[25] Wang YC, Kodur VKR. An approach for calculating the failure loads of unprotected concrete filled steel columns exposed to fire. STRUCT ENG MECH. 1999;7(2): 127-45.

[26] Wang YC. A simple method for calculating the fire resistance of concrete-filled CHS columns. J CONSTR STEEL RES. 2000;44(3): 203-23.

[27] Li GQ, He JL, Han LH. Load bearing Capacity of Fire resistance of Concrete Filled Steel Tubular Columns. Building Structure. 2001;31(01): 60-2.

[28] Han LH, Xu L, Feng JB, Yang YF. Fire Resistance and Fire Protective Cover of Concrete-Filled Steel Tubular Column. China Civil Engineering Journal. 2002;35(6): 6-13.

[29] Tan KH, Tang CY. Interaction Model for Unprotected Concrete Filled Steel Columns Under Standard Fire Conditions. J STRUCT ENG. 2004;130(9): 1405-13.

[30] Yu M. Research on the consecutive theory of concrete filled steel members under normal to high temperature and impact load [Shenzhen: Harbin institute of technology; 2011.

[31] Espinos A, Romero ML, Hospitaler A. Simple calculation model for evaluating the fire resistance of unreinforced concrete filled tubular columns. ENG STRUCT. 2012;42: 231-44.

[32] Espinos A, Romero ML, Hospitaler A. Fire design method for bar-reinforced circular and elliptical concrete filled tubular columns. ENG STRUCT. 2013;56: 384-95.

[33] Yu M, Zha X, Ye J, Wang B. A unified method for calculating fire resistance of solid and hollow concrete-filled steel tube columns based on average temperature. ENG STRUCT. 2014;71: 12-22.

[34] Yu M, Pei X, Xu L, Ye J. A unified formula for calculating bending capacity of solid and hollow concrete-filled steel tubes under normal and elevated temperature. J CONSTR STEEL RES. 2018;141: 216-25.

[35] Yu M, Xu H, Ye J, Chi Y. A unified interaction equation for strength and global stability of solid and hollow concrete-filled steel tube columns under room and elevated temperatures. J CONSTR STEEL RES. 2018;148: 304-13.

[36] Lie TT. Structural Fire Protection. New York: American Society of Civil Engineers, 1992.

[37] Wang ZH, Tan KH. Green's function solution for transient heat conduction in concrete-filled CHS subjected to fire. ENG STRUCT. 2006;63(7): 997-1007.

[38] Ministry Of Housing And Development. Technical code for concrete filled steel tubular structures. Beijing: China Building Industry Press, 2014.

[39] Ministry Of Housing And Development. Code for design of concrete structures. Beijing: China Building Industry Press, 2015.

[40] EN 1994-1-1:2004. Design of Composite Steel and Concrete Structure Part 1.1: General Rules and Rules for Buildings. EN 1994-1-2:2005: British Standards Institution, 2004.

[41] Ministry Of Housing And Development. Code for fire safety of steel structures in buildings. GB 51249-2017. Beijing: China planning press, 2017.

[42] Wickström U. A very simple method for estimating temperature in fire exposed concrete structures.: Swedish National Testing Institute, 1986.

[43] Chuyang T. An Interactive Formula For Fire Resistance Of Columns [Singapore: Nanyang Technological 
University; 2002.

[44] Dong-Kyu Kim, Sung-Mo Choi, Jin-Ho Kim, Kyung-Soo Chung, Park S. Experimental Study on Fire Resistance of Concrete-filled Steel Tube Column under Constant Axial Loads. Steel Structures. 2005(5): 305-13.

[45] Han L, Zhao X, Yang Y, Feng J. Experimental Study and Calculation of Fire Resistance of Concrete-Filled Hollow Steel Columns. J STRUCT ENG. 2003;129(3): 346-56.

[46] Han L, Yang Y, Xu L. An experimental study and calculation on the fire resistance of concrete-filled SHS and RHS columns. J CONSTR STEEL RES. 2003;59(4): 427-52. 